\title{
Yeast Membrane Lipid Imbalance Leads to Trafficking Defects toward the Golgi
}

Sara Elizabeth Woodman

As with any intellectual project, the content and views expressed in this thesis may be considered objectionable by some readers. However, this student-scholar's work has been judged to have academic value by the student's thesis committee members trained in the discipline. The content and views expressed in this thesis are those of the student-scholar and are not endorsed by Missouri State University, its Graduate College, or its employees.

Follow this and additional works at: https://bearworks.missouristate.edu/theses

Part of the Biology Commons

\section{Recommended Citation}

Woodman, Sara Elizabeth, "Yeast Membrane Lipid Imbalance Leads to Trafficking Defects toward the Golgi" (2017). MSU Graduate Theses. 3187.

https://bearworks.missouristate.edu/theses/3187

This article or document was made available through BearWorks, the institutional repository of Missouri State University. The work contained in it may be protected by copyright and require permission of the copyright holder for reuse or redistribution.

For more information, please contact BearWorks@library.missouristate.edu. 


\title{
YEAST MEMBRANE LIPID IMBALANCE LEADS TO TRAFFICKING DEFECTS TOWARD THE GOLGI
}

\author{
A Master's Thesis \\ Presented to \\ The Graduate College of \\ Missouri State University
}

\author{
In Partial Fulfillment \\ Of the Requirements for the Degree \\ Master of Science, Biology
}

By

Sara Elizabeth Woodman

May 2017 
Copyright 2017 by Sara Elizabeth Woodman 


\title{
YEAST MEMBRANE LIPID IMBALANCE LEADS TO TRAFFICKING \\ DEFECTS TOWARD THE GOLGI
}

\author{
Biology
}

Missouri State University, May 2017

Master of Science

Sara Elizabeth Woodman

\begin{abstract}
Protein recycling is an essential cellular process that involves endocytosis, intracellular trafficking, and exocytosis. In mammalian systems, membrane lipids (including cholesterol, sphingolipids, and phospholipids) play a pivotal role in protein recycling. To address this role in budding yeast, Saccharomyces cerevisiae, I utilized GFP-Snc1, a fluorescent marker for reporting the recycling pathway. Moderate to significant GFPSnc1 recycling defects occurred upon overexpression or inactivation of phospholipid, ergosterol, and sphingolipid biosynthesis enzymes, indicating that homeostasis of membrane lipid levels is prerequisite for proper protein recycling. Expression of a truncated version of GFP-Snc1 that cannot be recycled from the plasma membrane revealed that abnormalities in Snc1 localization in membrane lipid overexpression or underexpression mutants are not due to defects in the synthetic/secretory pathway, but rather in the intracellular trafficking pathway. Membrane lipid imbalance resulted in an accumulation of the late endosome marker Vps10-GFP, indicating trafficking from the endosomes to the Golgi may be being hindered, preventing recycling to the plasma membrane. To elucidate the possible mechanism for this trafficking hindrance, I stained the actin cytoskeleton, then quantified the percentage of cells with visible actin cables. Compared to wild-type cells, membrane lipid mutant cells exhibited lower levels of actin cables, indicating the actin cytoskeleton is disrupted upon membrane lipid imbalance. Taken together, my results show that impairment of proper recycling may be due to disruption of the actin cytoskeleton, which causes trafficking hindrance between the endosomes and Golgi.
\end{abstract}

KEYWORDS: protein recycling, endocytosis, yeast, intracellular trafficking, Snc1, actin, cell biology

This abstract is approved as to form and content

Kyoungtae Kim, PhD
Chairperson, Advisory Committee
Missouri State University




\title{
YEAST MEMBRANE LIPID IMBALANCE LEADS TO TRAFFICKING \\ DEFECTS TOWARD THE GOLGI
}

\author{
By \\ Sara Elizabeth Woodman \\ A Master's Thesis \\ Submitted to the Graduate College \\ Of Missouri State University \\ In Partial Fulfillment of the Requirements \\ For the Degree of Master of Science, Biology
}

May 2017

Approved:

Kyoungtae Kim, PhD

Paul L. Durham, PhD

Laszlo Kovacs, PhD

Julie Masterson, PhD: Dean, Graduate College 


\section{ACKNOWLEDGEMENTS}

First and foremost, I would like to express my sincerest gratitude to my committee chair Dr. Kyoungtae Kim, for his enthusiasm, support, and guidance throughout my time in his lab, both as an undergraduate and as a graduate student. I have learned and grown so much during my time in his lab, and I am grateful he allowed me that opportunity. I also want to thank my committee members, Dr. Paul Durham and Dr. Laszlo Kovacs for their valuable time and input during my time as a student at Missouri State University. Additionally, I would like to thank my colleagues and friends Samantha Fredrickson, Wes Short, Thomas Freeman, Pelin Makaraci, Tanner Hoog, Mariel Delgado Cruz, Chelsea Campbell, Angeline Rodriguez, Hyoeun McDermott, and Jared Smothers for their support, which truly means the world to me. Next, I would like to thank my family for always being there for me and supporting me throughout my educational journey. Finally, I would like to acknowledge the Biology Department and the Graduate College for their financial support.

I dedicate this thesis to my parents. 


\section{TABLE OF CONTENTS}



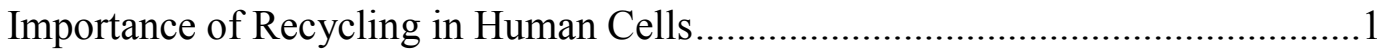

General Recycling Information..........................................................................



Problem Statement and Conclusions .............................................................13

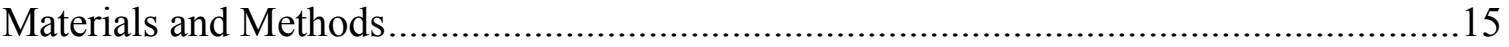

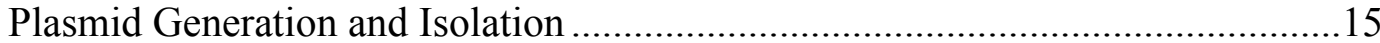

Creation of Mutant Strains and Treatment with Myriocin.....................................16

Cell Staining and Confocal Microscopy …………….......................................17

Vps10 Transformation and Quantification .....................................................19

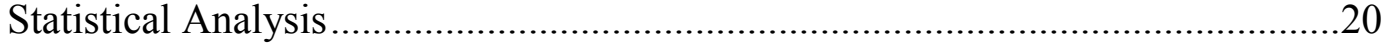

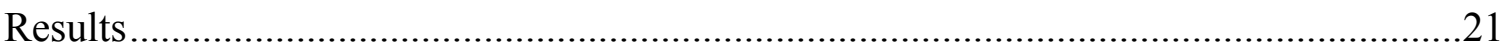

Importance of Membrane Lipid Balance in Proper Protein Recycling...................21

Late Endosome to Golgi Trafficking of GFP-Snc1 is Hindered............................24

Membrane Lipid Imbalance Disrupts Actin Cable Formation ..............................25

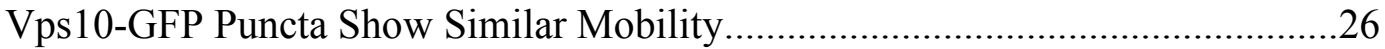

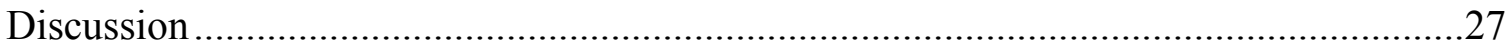

Lipid Imbalance and its Impact...................................................................2

Mechanism of Protein Recycling Defects...............................................................31






\section{LIST OF TABLES}

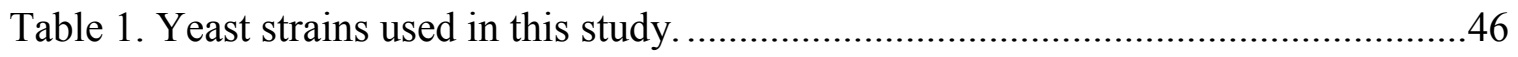

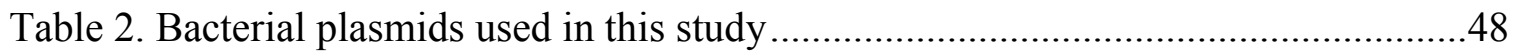

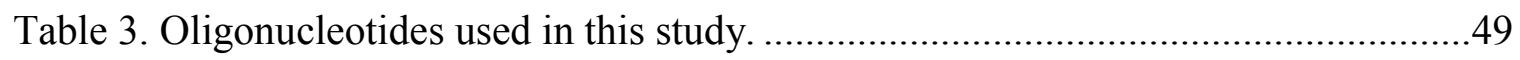




\section{LIST OF FIGURES}

Figure 1. Characterization of the localization of GFP-Snc1 in wild type and phospholipid mutant cells

Figure 2. Characterization of the localization of GFP-Snc1 in wild type, sphingolipid mutant and sphingolipid-overexpressing cells

Figure 3. Characterization of the localization of GFP-Snc1 in wild type, ergosterol mutant and ergosterol-overexpressing cells

Figure 4. Localization of Snc1-GFP-PEM in wild type and membrane lipid mutants......53

Figure 5. GFP-Snc1 puncta accumulate in phospholipid mutants .................................54

Figure 6. Vps10 puncta accumulate in membrane lipid mutants....................................55

Figure 7. Actin cables are diminished in membrane lipid mutants................................56

Figure 8. Average distance traveled by Vps10-GFP puncta.........................................57

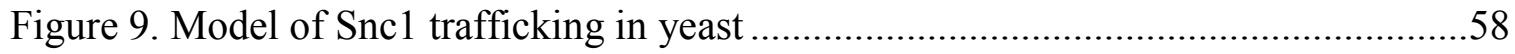

Figure 10. Model of trafficking defects observed due to membrane lipid imbalance .......59 


\section{INTRODUCTION}

\section{Importance of Recycling in Human Cells}

The ability to recycle various components, including proteins and membrane materials, is essential for maintaining cellular health. Rather than having to synthesize these elements de novo each time, recycling allows for the conservation of energy, enabling the cell to grow more rapidly, without the waste that would arise from discarding still-functional intracellular machinery. Defects in various recycling pathways can cause defects on a cellular level. For example, blockage of claudin-1 recycling in epithelial cells prevents proper formation of the epithelial barrier (Dukes et al., 2012), and inhibition of recycling can cause improper protein accumulation at the endoplasmic reticulum and Golgi body (Fujiwara et al., 1998; Storrie, 2005). On a systemic level, improper protein recycling has been implicated in a variety of neurodegenerative diseases, including amyotrophic lateral sclerosis (ALS), Parkinson's disease, and Alzheimer's disease (Fecto et al., 2014). When recycling is disrupted, protein aggregates can form, interfering with proper neuronal function and leading to a disease state (Douglas and Dillin, 2010).

The prominent hallmark of Alzheimer's disease is the accumulation of amyloid $\beta$ plaques within the brain, which can lead to hypometabolism within the prefrontal portion of the brain (Klupp et al., 2015). This accumulation is the result of improper protein trafficking and recycling within the cell. Specifically, defects in the function of the retromer complex, which mediates the movement of recycled proteins from the endosomes to the Golgi, have been implicated in the Alzheimer's disease process (Wang 
and Bellen, 2015). Additionally, modifications to the COPI complex, which coats vesicles during retrograde transport from the Golgi to the endoplasmic reticulum, have been shown to impact the localization and accumulation of amyloid $\beta$ plaques (Bettayeb et al., 2016). Taken together, these recycling defects cause problems in cognitive function for the estimated 5.4 million Americans currently suffering from Alzheimer's disease (Alzheimer's, 2016).

Recycling defects have also been implicated in Parkinson's disease, a neurodegenerative disease characterized by slowing and/or difficulty in moving, tremors, and balance and postural instability (Csoti et al., 2016; Fecto et al., 2014). During the progression of Parkinson's disease, $\alpha$ synuclein, which normally plays a role in the function of neurons and in the stress response, forms aggregates called Lewy bodies (Benskey et al., 2016). Mutations in the VPS35 component of the retromer complex have been associated with Parkinson's disease (Wang et al., 2016). These mutations have been shown to inhibit protein-protein interactions, leading to defects in endosome-Golgi recycling traffic, which may play a role in aggregate formation (McGough et al., 2014). Additionally, the small GTPases Rab11a and Rab13, which play roles in intracellular trafficking, have been found to promote clearance of $\alpha$ synuclein, and defects in steps mediated by these two proteins could lead to aggregate formation (Goncalves and Outeiro, 2016).

A greater understanding of the mechanisms of protein and membrane recycling will help shed light on possible biomedical and therapeutic targets, which will enable better management of diseases caused by recycling defects. Therefore, this introduction 
will focus on the in-depth process of protein recycling, particularly retrograde (endosome to Golgi) trafficking, and the effects of altered membrane dynamics on this process.

\section{General Recycling Information}

Among eukaryotic systems, the budding yeast Saccharomyces cerevisiae is one of the most well-studied models for the recycling pathway, owing to its ease of culture, genetic manipulability, and similarity to higher eukaryotic systems (Feyder et al., 2015). Through observation of the phenotypes of genetically modified strains, coupled with liveimaging, immunofluorescent staining (Keil and Hatzfeld, 2014), creation of pointmutations, fluorescent tagging (Schafer et al., 2016), and using monoclonal antibodies to label embedded membrane proteins (Blagojevic Zagorac et al., 2017), a detailed map of the recycling pathway has been constructed, along with determination of the major proteins involved in each step (Amberg et al., 2005; Blagojevic Zagorac et al., 2017).

Recycling of embedded membrane proteins begins with endocytosis at the section of the plasma membrane containing the proteins to be recycled. With the help of various protein complexes, a portion of the plasma membrane starts to curve inward, forming an invaginated pit, which is then pinched off to form a vesicle that contains the proteins to be recycled embedded in its membrane (Idrissi and Geli, 2014). From here, proteins can go through three possible routes. Multiple endocytosed vesicles fuse to form sorting or early endosomes, which can then recycle proteins through the first ("fast") recycling pathway, directly back to the plasma membrane, or send proteins along a second ("slow") recycling pathway, through sorting endosomes, and then back to the plasma membrane (Furuta et al., 2007; Lock and Stow, 2005). A third (retrograde) recycling pathway 
involves retrograde trafficking of proteins from the endosomes to the trans-Golgi network (TGN), followed by recycling back to the plasma membrane through the secretory pathway (Burd, 2011).

Many proteins and protein complexes are important in the recycling process. During endocytosis, the adaptor protein complex AP2 either associates directly with phosphatidylinositol (4,5)-bisphosphate (PIP2) present in the cell membrane, or is recruited via interaction with the cytoplasmic portions of receptor proteins embedded in the membrane (Robinson, 2004; Sorkin, 2004). The presence of AP2 allows the coat protein clathrin to be recruited to the plasma membrane, followed by binding of a variety of cargo proteins, which will be carried within the budding vesicle, to the embedded receptor proteins (Idrissi et al., 2008). Association of epsin/Ent1 with lipids in the clathrin-coated membrane permits recruitment of late coat proteins, which in turn promote actin association and polymerization, which causes invagination of the membrane (Fernandez-Golbano et al., 2014; Sen et al., 2012). Pinching off of the budded vesicle occurs through membrane remodeling promoted by the SH3 and F-BAR domains of amphiphysin/Rvs167 (Stanishneva-Konovalova et al., 2016), along with the action of the GTPase dynamin/Vps1, which wraps around the neck of the invaginating vesicle and constricts it, resulting in fission (Idrissi and Geli, 2014).

Once the vesicles have been pinched off, they move away from the plasma membrane, toward early endosomes via a yet-unknown mechanism that is likely associated with actin fibers (Toshima et al., 2016). Once at the early endosomes, proteins are sorted to the recycling or retrograde pathways through the action of the retromer 
complex (Varandas et al., 2016). This complex contains a three-protein core called the cargo recognition complex (CRC) which associates with various sorting nexin proteins that determine the ultimate destination of proteins sorted by the retromer (Burd and Cullen, 2014). Association with the sorting nexin Snx3 promotes cargo recycling directly back to the plasma membrane, while Snx27 shifts cargo transport to the retrograde pathway toward the TGN (Harterink et al., 2011). Vesicles are transported along microtubule (or possibly actin) fibers to the TGN, where docking and fusion can occur, through the action of v- and t-SNARE proteins, and possibly mediated by the Golgiassociated retrograde protein (GARP) complex (Chen et al., 2016b; Perez-Victoria et al., 2008). Once delivered to the TGN, proteins can then be sent back to the plasma membrane via the secretory pathway (Burd, 2011).

During intracellular trafficking, vesicles are carried to their target destinations by a variety of motor proteins, including kinesins, dyneins, and non-muscle myosins (Cheney and Baker, 1999; Hirokawa, 1998). Motor proteins attach to the vesicles they are carrying, and then hydrolyze ATP to generate energy "walk" along cytoskeletal fibers (microtubules in the case of kinesins and dyneins, and actin cables in the case of myosins) to the target location within the cell (Foth et al., 2006). Actin cables play a particularly important role in growth and cell division, because the formins Bnr1 and Bnil polymerize actin cables, allowing myosin II and V to deliver materials and organelles, such as mitochondria, to the areas of growth (Gao and Bretscher, 2009; Lo Presti et al., 2012). Additionally, myosin V has been shown to bind to secretory vesicles and transport them along actin cables toward the site of exocytosis (Schott et al., 1999). Due to actin's role as a track for motor proteins, defects in the actin cytoskeleton are 
likely to inhibit vesicular transport and thus impede intracellular trafficking and recycling.

One prominent example of retrograde trafficking is the yeast v-SNARE Snc1, which functions to mediate fusion of outgoing (secretory) vesicles with the plasma membrane, and is commonly used as a reporter for the retrograde trafficking pathway. Snc1 is localized to the plasma membrane, with wild-type cells exhibiting a polarized phenotype with the majority of the Sncl being found at the growing daughter bud, where the largest amount of secretory vesicle fusion is occurring (TerBush et al., 1996). Because Snc1 is internalized during the endocytosis process, trafficked via the retrograde pathway through the endosomes and TGN, and then back to the plasma membrane, the polarized plasma membrane phenotype of Snc1 serves as an indicator that the retrograde trafficking process is functioning normally (Wiederkehr et al., 2000).

Various proteins can be used as important markers within the retrograde pathway. In yeast, a second example of a protein that undergoes retrograde trafficking is the carboxypeptidase Y (CPY) receptor Vps10, which normally cycles between the endosomes and Golgi, performing its role in sorting and trafficking CPY (Marcusson et al., 1994). When fluorescently tagged, Vps10 serves as a good indicator of proper retrograde (endosome-to-Golgi) traffic, since defects in this portion of the pathway will result in Vps10 accumulation in the endosomes or misdirection to the vacuolar rim (Marcusson et al., 1994). Carboxypeptidase Y (CPY) is the ligand of Vps10, and normally binds to Vp10 in the Golgi and is trafficked to the endosomes, where it dissociates from Vps 10 and is then sent to the vacuole (Cereghino et al., 1995; Cooper and Stevens, 1996). CPY itself can be used as an indicator of proper anterograde (Golgi- 
to-endosome) traffic, as missorted CPY will be secreted from the cell, while properly sorted CPY will remain inside the cell (Jorgensen et al., 1999; Stolz and Wolf, 2012). In mammalian cells, mannose-6-phosphate (Man6P) receptor can be used for the same purpose as Vps10 in yeast, as a marker of proper endosome to Golgi traffic (Brown et al., 1986).

\section{Lipids in the Cell}

Lipids are a diverse class of nonpolar or semipolar organic molecules that, in contrast to nucleic acids and carbohydrates, are insoluble in water but soluble in nonpolar organic solvents (Fahy et al., 2009). Within the cell, lipids have many roles, including signaling, structural composition of membranes, and energy storage (Klug and Daum, 2014). Lipids can be synthesized de novo, or can betaken up from the environment, and used either directly or after modification (Tehlivets et al., 2007).

The membranes that form the outer boundary of the cell and the limits of organelles are made of three main categories of lipids: phospholipids, sphingolipids, and sterols (cholesterol, or the yeast alternative, ergosterol) (van Meer et al., 2008). Within each of these broad groupings; however, there are many molecular alterations that result in a wide range of different lipids that behave in diverse ways and at various intracellular

locations. Furthermore, cells alter the lipid composition within their membranes, based on the environment, in order to achieve optimal membrane performance (Martin et al., 2007).

Molecules in the first category of membrane lipids, phospholipids, consist of two fatty acid tails and a polar head group attached to a 3-carbon glycerol backbone. An 
extremely large number of different molecules with different physical properties can be formed within the phospholipid family by varying the length and degree of saturation of the fatty acid tails, or the molecular structure of the head group (Daum et al., 1998). Important lipids in this family include phosphatidylinositol (PI), an important precursor to several other phospholipids found within membranes throughout the cell (DeanJohnson and Henry, 1989; Nikawa et al., 1991). These downstream lipids include phosphatidylinositol phosphate [PI(4)P], which is important in yeast for secretion and in mammalian cells for recruitment of the adaptor protein AP-1 to the Golgi (Wang et al., 2003). In addition, phosphatidylinositol $(4,5)$-bisphosphate $\left[\mathrm{PI}(4,5) \mathrm{P}_{2}\right]$ is a phospholipid that has important roles at the plasma membrane by modulatating actin polymerization and vesicle formation (Doughman et al., 2003), and additionally playing a role in signaling and cold tolerance (Corcoles-Saez et al., 2016). $\mathrm{PI}(4,5) \mathrm{P}_{2}$ is synthesized through the action of the lipid kinase Mss4 (Audhya and Emr, 2003), and can be dephosphorylated back to PI(4)P or PI, through the action of the phosphatases Sj11, Sj12, and Sj13 (also known as Inp51, Inp52, and Inp53), thus modulating the composition of each species of phospholipid in the membrane (Guo et al., 1999). PIP 2 levels can be synthetically depleted using a temperature sensitive mutant, $m s s 4^{t s}$, grown at elevated temperatures (Audhya and Emr, 2003). Additionally, accumulation of $\mathrm{PIP}_{2}$ can be induced through deletion of SJL1, SJL2, or SJL3 (Guo et al., 1999).

Phospholipids play important roles nutritionally in brain development (Hellhammer et al., 2010; Liu et al., 2014), as well as possibly playing roles in proper brain function and in the prevention of neurodegenerative diseases (Nagai, 2012; Schipper et al., 2016). Phosopholipid consumption has also been linked to resistance 
against certain kinds of bacteria and viruses (Fuller et al., 2013; Veereman-Wauters et al., 2012). Interestingly, certain kinds of phospholipids have also been found to have antiproliferative properties, leading to speculation about the possible applications for lipids in cancer therapies (Castro-Gomez et al., 2016; Kuchta-Noctor et al., 2016).

The second category of membrane lipids, sphingolipids, is composed of the long chain base (a long carbon chain that terminates in an amine group and several hydroxyl groups) parent molecule sphingosine, as well as its derivatives: ceramides, sphingomyelins, cerebrosides, and gangliosides (Schneiter, 1999). Sphingolipids are important parts of cell membranes, but also have signaling roles via regulating various aspects of the yeast cell cycle from cell division through apoptosis (Spincemaille et al., 2014). Additionally, sphingolipids have been shown to play a role in mitochondrial function and gene expression (Kitagaki et al., 2009; Kitagaki et al., 2007). The first step in sphingolipid production is mediated by Lcb1 and Lcb2, which together form the serine palmitoyltransferase complex (Buede et al., 1991; Nagiec et al., 1994). This step can be inhibited through addition of the atypical amino acid myriocin, resulting in a dosedependent depletion of sphingolipids within the treated cells (Miyake et al., 1995).

Sphingolipids have been found to have various roles in signaling and regulation of cellular processes. Specifically, sphingolipids play a role in regulating the cell cycle, apoptosis, cell survival (Garcia-Gil et al., 2017; Ng et al., 2017), and inflammation (Gualtierotti et al., 2017; Ueda, 2017). Some examples of sphingolipids as signaling molecules include their role in regulating survival and apoptosis of murine neuroblasts (Bruno et al., 2017), and their postulated role in development of diabetes through contributing to apoptosis of pancreatic $\beta$-cells (Ng et al., 2017). Sphingolipids also have a 
role in recycling of endocytic membranes (Lima et al., 2017), and in intracellular trafficking during the life cycle of some viruses, including hepatitis $\mathrm{B}$ and $\mathrm{C}$ viruses (Zhang et al., 2016). Overall, sphingolipids play important roles as biological signaling molecules, and their imbalance would be likely to cause defects in cell function.

Molecules in the third category of membrane lipids, sterols, have a characteristic pattern of four interlocking hydrocarbon rings, rather than the long hydrocarbon chains present in phospholipids and sphingolipids. Sterols interact with sphingolipids in the cell membrane, playing an important role in endocytosis, transport of amino acids throughout the cell, energy production, and maintenance of membrane stability during cellular stress (Dupont et al., 2011; Parks et al., 1995; Pichler and Riezman, 2004). Among the multiple sterols known to play important roles within the cell, cholesterol and ergosterol are the most prominent in mammalian and yeast cells, respectively (Ikonen and Jansen, 2008).

Ergosterol is similar to cholesterol but has a slightly altered structure and function, and is synthesized from its precursor, zymosterol, via a complex multi-step process involving the $E R G$ genes (Zinser et al., 1993). Knockout or overexpression of these genes can result in an accumulation of the ergosterol precursors or ergosterol within the cell membrane, altering cellular behavior and function (Barton et al., 1974). The final steps of ergosterol synthesis are catalyzed by $E R G 6, E R G 2, E R G 3, E R G 5$, and $E R G 4$, and knockout of these genes results in cells that are viable, but have abnormal phenotypes of varying degrees of severity due to the accumulation of ergosterol precursors (Lees et al., 1995). Of these five genes, $E R G 6, E R G 3$, and $E R G 4$ have the greatest impact on cell physiology. In strains with any of these genes deleted, plasma membrane stability is compromised, resulting in increased sensitivity to changes in environmental water (erg6 $\Delta$ 
cells), decreased ability of the cell to maintain membrane potential (erg6 $\Delta$ and $\operatorname{erg} 4 \Delta$ cells), variations in size and morphology (erg $4 \Delta$ cells), and altered susceptibility to antifungal agents (erg64, $\operatorname{erg} 3 \Delta$, and $\operatorname{erg} 4 \Delta$ cells) (Dupont et al., 2011; Kodedova and Sychrova, 2015).

Cholesterol (ergosterol) has important roles in many membranes, as well as being important as a precursor of steroid hormones (Garcia-Ruiz et al., 2016). During the steroid synthesis process, cholesterol is encorporated into lipid droplets present in the cytoplasm, then trafficked to the mitochondria by SNARE proteins (Kraemer et al., 2017). The concentration of cholesterol in various organelles has been shown to be important in the trafficking of African swine flu virus, (Cuesta-Geijo et al., 2015), and trafficking of hedgehog ligands, which are important in the regulation of developmental processes (Chen et al., 2016a), and integrins, which are important for interaction of cells with the extra-cellular matrix (Garcia-Melero et al., 2016). Improper accumulation of cholesterol in the mitochondria has been one factor implicated in the ability of cells to avoid apoptosis, leading to cancer (Garcia-Ruiz et al., 2016; Ribas et al., 2016).

Alteration of membrane lipid concentrations is known to play a role in a variety of diseases. For example, in mouse models of cystic fibrosis, membrane lipid imbalance was found in affected organs, but administration of docosahexaenoic acid ( $\mathrm{Ng}$ et al.) remedied both the lipid imbalances and disease pathology (Freedman et al., 1999). Additionally, alterations in lipid concentration have been found to play a role in amyloid formation, which can contribute to damage of pancreatic $\beta$-cells, leading to type 2 diabetes (Zhang et al., 2017) or to the death of neurons, leading to Alzheimer's disease (Brown and Bevan, 2017). Furthermore, alterations of membrane lipids have been implicated in multiple 
sclerosis and in the progressive neurodegenerative condition Niemann-Pick C Disease, suggesting that lipid imbalance is toxic for neural cells (Hon et al., 2009; Vance, 2006).

Altered membrane lipid concentration has been reported in other diseases, although the imbalance may be a result, rather than a cause, of the disease. One of these findings is that levels of cholesterol and unsaturated fatty acids increased in the membranes of platelets isolated from women with preeclampsia (Garzetti et al., 1993). Patients with sickle cell anemia were found to have a lack of eicosapentaenoic acid (EPA) and docosahexaenoic acid (Ng et al.) making up the membranes of their erythrocytes, and supplementation of EPA and DHA has been proposed as a therapy to reduce the severity of the anemia in these patients (Connor et al., 1997; Ren et al., 2005). Additionally, membrane lipid imbalance, specifically in immune cells such as macrophages, has been proposed to be involved in the development of atherosclerosis (Schmitz and Grandl, 2008).

At the cellular level, membrane lipids play an important role, especially at the plasma membrane. Lipids are important for determining the curvature of the membrane, which may influence interactions with nearby cells (Kuypers, 2007), as well as impacting the secondary structure of proteins that interact with the membrane from outside the cell (Mishig-Ochir et al., 2016). Membrane lipid imbalance can also disrupt proper functioning of membrane proteins, including G protein-coupled receptors (GPCRs), because proteins that are embedded in the membrane interact with membrane lipid components (Marino et al., 2016).

Although the role of lipids in some aspects of cellular physiology, such as in endocytosis, is well studied, potential impacts of lipid imbalance on intracellular 
retrograde trafficking is not fully understood. In mammalian cells, cholesterol depletion has been found to interfere with trafficking of integrins, which are important in cell adhesion to the extracellular matrix, leading to altered cell migration abilities (Reverter et al., 2014). Furthermore, cholesterol imbalance results in mislocalization of t-SNAREs that are important in the exocytic process, while restoration of proper cholesterol levels restores proper exocytic trafficking (Reverter et al., 2011). Additionally, since the concentration of membrane lipids determines proper vesicle trafficking (Johansen et al., 2012), it is not surprising that depletion of sphingolipids in yeast results in improper targeting of the v-SNARE Snc1 (Tani and Kuge, 2012). Since lipid imbalance is characteristic of diseases such as Alzheimer's, Niemann-Pick type C Disease, and cardiovascular disease (Ikonen and Holtta-Vuori, 2004), a deeper understanding of the role of lipids within the cell, particularly in retrograde protein trafficking, is crucial. Since S. cerevisiae is eukaryotic and has protein trafficking similar to that of mammalian cells, it can be used to study membrane lipid dynamics and their relationship to retrograde protein trafficking, and potentially shed light on the mechanisms of diseases involving membrane lipid imbalance.

\section{Problem Statement and Conclusions}

My study had two major aims. Firstly, I wanted to determine the role of the three categories of membrane lipids (phospholipids, sphingolipids, and ergosterol) in proper protein recycling, primarily using the recycling marker GFP-Snc1. Secondly, I sought to investigate the mechanistic reason for recycling defects in membrane lipid imbalance 
cases. To address these goals, I used a variety of techniques including cloning, confocal microscopy, and cell staining.

Here I present evidence that lipid homeostasis is required for proper retrograde trafficking of proteins from the endosomes to the Golgi, in order for recycling back to the plasma membrane through the secretory pathway. Furthermore, membrane lipid imbalance likely contributes to retrograde trafficking defects from the early and late endosomes to the Golgi, through disrupting actin cable formation, which is essential for retrograde vesicular trafficking. 


\section{MATERIALS AND METHODS}

\section{Plasmid Generation and Isolation}

Yeast genomic DNA was isolated from wild type yeast (KKY 0002, Table 1) using epicenter ${ }^{\circledR}$ MasterPure ${ }^{\mathrm{TM}}$ Yeast DNA Purification Kit (Cat No. MC85200). E. coli HST08 cultures containing the plasmid pRS314 TEF (KKD 293, Table 2) were grown overnight on Luria Broth (LB) plates supplemented with ampicillin. An individual colony was used to inoculate a $3 \mathrm{ml}$ culture of LB, supplemented with ampicillin to a final concentration of $100 \mu \mathrm{g} / \mathrm{ml}$. The plasmid was isolated from the $3 \mathrm{ml}$ culture using QIAprep Spin Miniprep Kit (Cat No./ID: 27106), following the protocol provided in the kit, with elution being performed using PCR-grade water. Plasmid concentration was determined using nanodrop equipment, then run on a $1 \%$ agarose gel to verify expected plasmid size.

The Golgi marker Ggal DNA sequence was copied from the template DNA using Phusion ${ }^{\circledR}$ Green High-Fidelity DNA Polymerase Kit (Thermo Scientific ${ }^{\mathrm{TM}}$, Cat. No. F534L) and primers KKP726 and KKP797 (Table 3), following the protocol provided by the manufacturer. Initial denaturation was performed at $98{ }^{\circ} \mathrm{C}$ for 2 minutes, followed by 34 cycles of denaturation at $98^{\circ} \mathrm{C}$ for 10 seconds, annealing at $63{ }^{\circ} \mathrm{C}$ for 30 seconds, and extension at $72{ }^{\circ} \mathrm{C}$ for 52 seconds $(1.7 \mathrm{~kb}$ at 30 seconds/kb). Final extension was performed at $72{ }^{\circ} \mathrm{C}$ for 7 minutes. A portion of the PCR reaction then was run on a $1 \%$ agarose gel to verify amplification. The PCR product was purified using Macherey Nagel NucleoSpin ${ }^{\circledR}$ Gel and PCR Clean-up kit (Ref. No. 740609.250), and the PCR product and vector were digested using Not1 and BamHI FastDigest Enzymes (Thermo 
Scientific ${ }^{\mathrm{TM}}$, Cat. No. FD0055 and FD0594) for 60 minutes at $37^{\circ} \mathrm{C}$, followed by thermal inactivation for 15 minutes at $85{ }^{\circ} \mathrm{C}$. The resulting digest was run on a $1 \%$ agarose gel, then gel purification was performed using the previously mentioned kit. The vector and insert were ligated at $16{ }^{\circ} \mathrm{C}$ for 16 hours. Stellar ${ }^{\mathrm{TM}}$ Competent Cells (Clontech, Cat. No. 636766) were transformed with the ligated vector, following the protocol provided by the company. Colonies were checked via colony PCR to verify Gga1 insertion.

Gga1 was C-terminally tagged with mRFP. Briefly, pRS314 TEF Gga1 (KKD317) was isolated as described above. mRFP was cut from a previously isolated vector, Ste2-mRFP (KKD145), and inserted into the vector using the BamHI and XhoI restriction sites, then transformed into Stellar ${ }^{\mathrm{TM}}$ Competent Cells (Clontech, Cat. No. 636766) following the procedure detailed above. Colony PCR was performed to verify mRFP insertion, then the plasmid was isolated from bacterial culture. A portion of the bacterial strain was saved for future use (KKD319).

Yeast cultures in the mid log phase $\left(\mathrm{OD}_{600} 0.6-0.8\right)$ were transformed following the one-step transformation protocol (Chen et al., 1992). Plasmid insertion was confirmed using yeast colony PCR.

\section{Creation of Mutant Strains and Treatment with Myriocin}

Mutant strains were created through knockout of genomic genes using auxotrophic markers. Cells were cultured for $16-18$ hours at $37^{\circ} \mathrm{C}$ with shaking, or until cultures reached mid log phase $\left(\mathrm{OD}_{600}\right.$ 0.6-0.8). Cells were imaged using a spinning disc confocal microscope. 
The TEF promoter was added to pRS425 (KKD126) using the SacI and NotI restriction sites, following the above protocol. The resulting plasmid was saved (KKD233) and used for LCB1 insertion. LCB1 was copied by PCR from template genomic DNA using primers KKP731 and KKP732, then inserted using the BamHI and XhoI restriction sites, and saved as KKD281. The plasmid was used in yeast to create a strain that overexpressed LCB1. An overexpression vector was also created for Erg4, through addition of Erg4 to KKD233 using the Bam HI and XhoI restriction sites, and using primers KKP749 and KKP750 for amplification, according to the above protocol.

For myriocin treatment, wild type yeast (KKD1525) was cultured for 16-18 hours at $30{ }^{\circ} \mathrm{C}$ with shaking, or until cultures reached early log phase ( $\left.\mathrm{OD}_{600} 0.3-0.4\right)$.

Untreated cells were used as a control, while experimental cultures were treated with myriocin to final concentrations of $0.0167 \mu \mathrm{g} / \mathrm{ml}, 0.167 \mu \mathrm{g} / \mathrm{ml}, 1.67 \mu \mathrm{g} / \mathrm{ml}$, and 16.7 $\mu \mathrm{g} / \mathrm{ml}$. Treated cultures were grown for $2-2.5$ hours at $30^{\circ} \mathrm{C}$ with shaking and then imaged using confocal microscopy.

\section{Cell Staining and Confocal Microscopy}

For FM 4-64 staining, yeast wild-type and mutant strains were cultured for 16-18 hours at $30{ }^{\circ} \mathrm{C}$ with shaking, or until cultures reached mid log phase ( $\left.\mathrm{OD}_{600} 0.6-0.8\right)$. Cells were harvested using an Eppendorf tabletop centrifuge (Model No. 5418). Cells were washed with cold synthetic defined (SD) complete media, then resuspended in cold SD complete. FM ${ }^{\circledR}$ 4-64 dye (Thermo Fisher Scientific, Cat. No. T3166) was added to a final concentration of $0.12 \mathrm{mM}$, and cells were incubated 10 minutes on ice. Cells were harvested at $4{ }^{\circ} \mathrm{C}$, then washed twice at $4{ }^{\circ} \mathrm{C}$ using ice cold SD complete. Cells were 
resuspended in cold SD complete, then kept on ice until imaging. Images were taken using the spinning confocal microscope, within 7 minutes of removing cells from ice. Cells showing FM® 4-64 staining that had already reached the vacuole were omitted from quantification. Three sets of 30 cells each were quantified per strain, and statistical analysis was performed to determine the mean, standard deviation, and p-value (using Student's t-test, comparing mutant strains to the control strain).

For actin staining, yeast wild type and mutant strains were cultured for 16-18 hours at $30^{\circ} \mathrm{C}$ with shaking, or until cultures reached early log phase ( $\mathrm{OD}_{600}$ of $\left.0.3-0.6\right)$. Cells were harvested by spinning at $1000 \mathrm{rpm}$ for 10 minutes, the supernatant was removed, then cells were resuspended in the appropriate media (SD complete or dropout medias). Cells were fixed, with gentle agitation, for 60 minutes by the addition of formaldehyde to the liquid media, with a final formaldehyde concentration of $4 \%$. Following fixation, cells were harvested, the supernatant was removed, and cells were washed using 1X PBS, then resuspended in 1X PBS. Cells were sonicated on ice for two pulses of 30 seconds each, using a Branson Sonifier ${ }^{\circledR}$ ultrasonic hydrogenator , allowing time between pulses for the sample to cool. Following sonication, cells were harvested and resuspended in $1 \mathrm{X}$ PBS. Cells were treated with Triton X-100 to permeabilize the membrane and Texas Red to stain the actin fibers, at final concentrations of $0.1 \%$ and 3.3 $\mu \mathrm{M}$, respectively. Cells were stained in the dark with gentle agitation for 20-30 minutes. Following staining, cells were harvested, washed 3 times using 1X PBS, and imaged using the spinning disc confocal microscope. Three sets of 30 cells each were quantified per strain for presence or absence of visible actin cables, and statistical analysis was 
performed to determine the mean, standard deviation, and p-value (using Student's t-test, comparing mutant strains to the control strain).

All strains were grown to mid log phase $\left(\mathrm{OD}_{600} 0.6-0.8\right)$ prior to visualization. Visualization of fluorescently labeled cells was performed using an Olympus IX81 inverted system microscope equipped with a Yokogawa CSUXI spinning disk head. Images were obtained using a 100X PlanApo oil immersion objective lens (numerical aperture 1.4), and were captured using a Hamamatsu ImagEM CCD camera and $3 \mathrm{i}$ Slidebook6 software. Simultaneous multi-color imaging was performed using a Photometrics ${ }^{\circledR}$ DV2 image splitter.

\section{Vps10 Transformation and Quantification}

Competent cells were created from wild-type and mutant strains, to allow for genomic transformation (Knop et al., 1999). Vps10-GFP PCR product was copied from the template plasmid (primers KKP773 and KKP774) and verified by running on a 1\% agarose gel, then imaging to observe band presence. Competent cells were transformed using the PCR product, then plated on selective media (Knop et al., 1999). Plates were incubated at $30{ }^{\circ} \mathrm{C}$ in a stationary incubator until colonies were grown, then stored at $4{ }^{\circ} \mathrm{C}$. To test for successful transformation, cells were checked for fluorescence using a spinning confocal microscope. Successfully transformed colonies were selected for each strain, and grown in selective liquid media for $16-18$ hours at $30{ }^{\circ} \mathrm{C}$ with shaking. Cells were imaged using a spinning disc confocal ( 3 sets of 30 cells per strain), and the number of visible puncta were quantified. 
To track Vps10 puncta, cells were live imaged at 2 images $/ \mathrm{sec}$ for $60 \mathrm{sec}$. For each strain, 10 puncta that persisted for at least 15 seconds were found and tracked manually using ImageJ software from first appearance until 15 seconds had elapsed. Using Excel, the distance traveled between frames was calculated using the distance formula, then summed to find the total distance traveled. Statistical analysis was performed to determine the mean, and standard deviation, and Student's t-test was used to determine the p-value (control vs. mutant strains).

\section{Statistical Analysis}

For all experiments, quantification was performed by counting a minimum of 30 cells in three individual sets. Statistical analysis was performed to determine the mean, and standard deviation of the three sets, and Student's t-test (two-tailed, equal variances) was used to determine the p-value (control vs. mutant strains). Statistical significance was defined as a p-value of less than 0.05 . 


\section{RESULTS}

\section{Importance of Membrane Lipid Balance in Proper Protein Recycling}

Cholesterol concentration has been shown to play an important role in the localization of SNAREs to the endosomes and Golgi (Enrich et al., 2015), and alterations in membrane lipid composition have been shown to result in alterations in intracellular trafficking, specifically in trafficking of Shiga toxin in mammalian cells (Kavaliauskiene et al., 2014). This prompted us to investigate specifically the impacts of altering the concencentration of three key membrane lipids (phospholipids, sphingolipids, and ergosterol) on retrograde protein trafficking. To track proper functioning of this pathway, I used GFP-tagged Snc1, which has been well established as a marker of protein recycling (Hettema et al., 2003; Ma et al., 2016). Snc1 is a transmembrane protein that is synthesized at the ER and then trafficked through the Golgi to the plasma membrane in the secretory pathway (Lewis et al., 2000). Snc1 recyling involves three steps: endocytosis; retrograde trafficking from the early endosomes to Golgi; and transport back to the plasma membrane (Hettema et al., 2003). When the recycling pathway is functional, the majority of the Snc1 protein is trafficked to the daughter bud (polarized), and few internal puncta are seen (TerBush et al., 1996). I hypothesized that disturbance of membrane lipid balance would likely result in defects in the recycling of Snc1, resulting in loss of the polarized phenotype due to mistargeting of Snc1.

To test the effect of imbalance of $\mathrm{PIP}_{2}$, an important phospholipid, on Snc1 and its recycling, I used mutant strains that caused overexpression or depletion of $\mathrm{PIP}_{2}$. In $m s s 4^{t s}$ cells grown at elevated temperatures $\left(37^{\circ} \mathrm{C}\right)$, depletion of $\mathrm{PIP}_{2}$ is observed (Audhya and 
Emr, 2003), while single or double deletion of $S J L 1, S J L 2$, or $S J L 3$ results in accumulation of $\mathrm{PIP}_{2}$ (Guo et al., 1999). I hypothesized that imbalance of $\mathrm{PIP}_{2}$ would result in Snc1 recycling defects. Consistent with my hypothesis, over or underexpression of phospholipids was found to inhibit proper GFP-Snc1 recycling. While $85.4 \% \pm 6.7$ of wild-type cells exhibited the normal, polarized GFP-Snc1 phenotype, the percentage of cells with normal phenotype dropped to $31.3 \% \pm 7.3$ in sjll $1 \Delta$ cells $(\mathrm{p}<0.01), 30.3 \% \pm 8.2$ in $s j l 2 \Delta$ cells $(\mathrm{p}<0.01)$, and $4.0 \% \pm 3.4$ in $m s s 4^{t s}$ cells $(\mathrm{p}<0.001)$

(Fig. 1A). Knockout of multiple genes in the phospholipid degradation pathway had even lower levels of GFP-Snc1 polarization, with only $11.6 \% \pm 8.1$ of $s j l 1 \Delta s j l 2 \Delta$ cells $(\mathrm{p}<0.001)$ and $0.7 \% \pm 1.4$ of $s j l 2 \Delta s j l 3 \Delta$ cells $(\mathrm{p}<0.001)$ showing the polarized phenotype (Fig. 1B). The phospholipid mutant strains showed a variety of abnormal phenotypes (Fig. 1A). In some strains, GFP-Snc1 was found at the membrane, but a loss of polarization was observed, while $m s s 4^{t s}$ cells showed almost completely internal accumulation of GFP-Snc1, mostly in vacuole-like membrane bound organelles, with a lack of GFP-Snc1 at the membrane. Although strains with a single gene knocked out ( $\operatorname{lll} 1 \Delta, s j l 2 \Delta$ ) exhibited moderate defects in GFP-Snc1 localization, knockout of two genes involved in phospholipid synthesis $(s j l 1 \Delta s j l 2 \Delta, s j l 2 \Delta s j l 3 \Delta)$ led to more severe defects.

To test the effect of altered sphingolipid levels, sphingolipid depletion was achieved by treating cells with varying levels of the pharmacological agent myriocin, which inhibits the first step in sphingolipid production (Miyake et al., 1995). The first step in sphingolipid synthesis is catalyzed by the LCB1 gene product (Buede et al., 1991), so sphingolipid overproduction was induced through expression of the $L C B 1$ gene 
under the strong $T E F$ promotor. Alteration of sphingolipid levels also led to defects in GFP-Snc1 polarization (Fig. 2A and Fig. 2B). GFP-Snc1 was polarized in $86.3 \% \pm 0.9$ of wild-type cells, while addition of the pharmacological agent myriocin resulted in lower frequencies of polarization (Fig. 2B). GFP-Snc1 was polarized in $70.1 \% \pm 2.6(\mathrm{p}<0.01)$, $41.2 \% \pm 11.3(p<0.05), 25.7 \% \pm 3.8(p<0.01)$, and $14.2 \% \pm 4.3(p<0.001)$ of cells treated with $0.0167 \mu \mathrm{g} / \mathrm{ml}, 0.167 \mu \mathrm{g} / \mathrm{ml}, 1.67 \mu \mathrm{g} / \mathrm{ml}$, and $16.7 \mu \mathrm{g} / \mathrm{ml}$ myriocin, respectively (Fig. $2 \mathrm{~A})$. With the exception of the $T E F-L C B 1$ strain, sphingolipid mutants were broadly depolarized, with even membrane staining, but showed few internal puncta. Although even low levels of myriocin caused depolarization, higher levels led to more severe levels of GFP-Snc1 depolarization (Fig. 2A). Interestingly, overproduction of Lcb1 under the $T E F$ promoter resulted in a phenotype similar to that seen in $m s s 4^{t s}$ cells, with severe accumulation of GFP-Snc1 in internal puncta and a polarized phenotype being present in only $7.0 \% \pm 1.4$ of cells ( $<<0.001$ ), a very severe loss of GFP-Snc1 polarization (Fig. $2 \mathrm{~A}$, B). These results indicate that sphingolipid balance is crucial for proper protein recycling.

The synthesis of ergosterol requires many steps, with some of the terminal steps being catalyzed by the gene products of ERG3, ERG4, and ERG6, so knockout mutants of these genes were used to deplete ergosterol levels in the cell (Lees et al., 1995). Additionally, expression of $E R G 4$ under the $T E F$ promoter was used to produce an overaccumulation of ergosterol. While alteration of ergosterol levels impacted GFP-Snc1 localization, the effect was not as severe as that seen in phospholipid or sphingolipid imbalance cells. Compared to $87.5 \% \pm 2.0$ of wild type, ergosterol depletion mutants showed decreased polarization, with $72.4 \% \pm 1.7$ of $\operatorname{erg} 3 \Delta$ cells $(\mathrm{p}<0.001), 37.5 \% \pm 5.7$ of $\operatorname{erg} 6 \Delta$ cells $(\mathrm{p}<0.01), 41.5 \% \pm 4.1$ of $\operatorname{erg} 4 \Delta \operatorname{erg} 6 \Delta$ cells $(\mathrm{p}<0.001)$ exhibiting the 
polarized phenotype. In TEF-ERG4 cells only $40.6 \% \pm 4.4$ of cells $(\mathrm{p}<0.001)$ exhibited a polarized GFP-Snc1 phenotype (Fig. 3A and Fig. 3B). Based on these data, alteration of ergosterol levels did not result in as strong of an impact on the localization of GFP-Snc1 as alteration of phospholipid and sphingolipid levels. Overall, however, imbalance of each of the three membrane lipid classes resulted in defects of varying severity in recycling of GFP-Snc1.

In order to exclude the possibility that the secretory portion of the recycling pathway (from the Golgi to the plasma membrane) is impaired in membrane lipid mutants, I introduced GFP-Snc1-PEM, a truncated form of Snc1 that can be transported to the plasma membrane but cannot be endocytosed, to wild type and membrane lipid mutants. Regardless of the strain, GFP-Snc1-PEM localization in mutant strains was similar to wild type (Fig. 4). In all strains, GFP-Snc1-PEM showed even staining around the plasma membrane, and a complete lack of internal puncta, indicating secretion from the Golgi to the plasma membrane is normal.

\section{Late Endosome to Golgi Trafficking of GFP-Snc1 is Hindered}

Internal puncta of GFP-Snc1 were seen in a variety of lipid synthesis mutants, but the internal accumulation of GFP-Snc1 was most pronounced in phospholipid mutants (Fig. 1A). Therefore, I quantified the number of GFP-Snc1 puncta in wild type and phospholipid phospholipid mutant strains. Compared to an average of $4.2 \pm 0.5$ puncta per cell in wild type, phospholipid mutant strains showed increased numbers of GFPSnc1 puncta, with $8.5 \pm 0.2(\mathrm{p}<0.001), 6.9 \pm 0.2(\mathrm{p}<0.001), 10.2 \pm 0.8(\mathrm{p}<0.01)$, and 8.5 $\pm 1.35(\mathrm{p}<0.05)$ puncta per cell in $s j l 1 \Delta$, sjl2 $\Delta$, sjll $1 \Delta j l 2 \Delta$, and $s j l 2 \Delta s j l 3 \Delta$, respectively 
(Fig. 5). Based on these results, GFP-Snc1 is accumulated within the cell, indicating trafficking from the early endosomes to the Golgi is hindered.

To test whether trafficking from the late endosomes to the Golgi was hindered in phospholipid mutant strains, the late endosome marker Vps10-GFP was expressed in these cells. Quantification of the average number of Vps10-GFP puncta present in wildtype and mutant strains revealed significant Vps10 accumulation in mutant strains. Accumulation was also seen in $b n r 1 \Delta$ and $b n r l b n i^{1-12}$, which are difficient in the ability to make actin cables (Buttery et al., 2007), indicating actin is important in the retrograde trafficking process (Fig. 6A). Compared to an average of $6.1 \pm 0.1$ puncta per cell in


$1.0(\mathrm{p}<0.01), 10.7 \pm 0.9(\mathrm{p}<0.01), 12.3 \pm 0.9(\mathrm{p}<0.01), 9.1 \pm 0.3(\mathrm{p}<0.01)$, and $11.8 \pm$ $0.8(\mathrm{p}<0.01)$ puncta per cell, respectively (Fig. 6B). Based on these results, membrane lipid imbalance results in accumulation of $\mathrm{Vps} 10$ within the cell, indicating a defect in late endosome to Golgi trafficking.

\section{Membrane Lipid Imbalance Disrupts Actin Cable Formation}

Alterations of the levels of PI4P within the endosomal membrane through the action of VAP has been shown to indirectly alter nucleation of actin, through disrupting functioning of the WASH complex (Dong et al., 2016). Based on this information, I hypothesized that membrane lipid imbalance in general would likely interfere with proper actin cytoskeleton/cable formation. To test for this, I fixed and stained wild-type and membrane lipid imbalance cells. Compared to the high proportion of wild type cells $(62.3 \% \pm 6.6)$ that exhibited visible actin cables (Fig. 7A), only $29.2 \pm 6.0$ of sjll $\Delta$ cells 
( $<<0.01), 26.3 \% \pm 7.6$ of $s j l 2 \Delta$ cells $(\mathrm{p}<0.01), 23.3 \% \pm 7.4$ of $s j l 1 \Delta s j l 2 \Delta$ cells $(\mathrm{p}<0.01)$

$16.5 \% \pm 7.4$ of $s j l 2 \Delta s j l 3 \Delta$ cells $(\mathrm{p}<0.01)$, and $28.6 \% \pm 11.0$ of $m s s 4^{t s}$ cells $(\mathrm{p}<0.05)$ (Fig.

7B) demonstared actin cables. Based on these results, the actin cytoskeleton is likely highly fragmented in membrane-imbalance mutants.

\section{Vps10-GFP Puncta Show Similar Mobility}

Since the number of Vps10 puncta was elevated and actin cable defects were observed in membrane lipid mutants, I wished to determine whether the mobility of the puncta was impaired in mutant strains. To do this, I used time-lapse images and tracked the movement of Vps10 puncta over time. Vps10 puncta in wild-type and membrane lipid imbalance cells showed similar rates of movement, total distances traveled, and distance from point of origin (Fig 8). In the total 15 seconds of tracking, Vps10-GFP puncta in wild-type cells traveled an average total distance of $4.9 \pm 0.9 \mu \mathrm{M}$, while puncta traveled $4.3 \pm 0.7 \mu \mathrm{M}$ in sjll $1 \Delta$ cells, $5.0 \pm 1.5 \mu \mathrm{M}$ in sjl2 $2 \Delta$ cells, and $4.7 \pm 0.7 \mu \mathrm{M}$ in sjll $\Delta$ sjl2 $\Delta$ cells (Fig. 8). None of the mutant strains had statistically significantly different results from the control strains. Based on these results, motility of puncta in these strains does not appear to be impaired. 


\section{DISCUSSION}

Findings from my study have highlighted the importance of a correct balance of sphingolipids, phospholipids, and ergosterol in the membrane in order to facilitate proper retrograde trafficking of proteins in yeast. These findings have important implications for the possible mechanisms of diseases that cause loss of membrane lipid homeostasis in eukaryotic organisms. Additionally, my results indicate that membrane lipid imbalance leads to the fragmentation of intracellular actin cables, and to the accumulation of cargoes at the endosomes.

\section{Lipid Imbalance and its Impact}

Lipids have many biological roles, from roles in brain fuction and development (Hellhammer et al., 2010; Liu et al., 2014; Nagai, 2012), to roles in cell cycle regulation and cell signaling (Garcia-Gil et al., 2017; Ng et al., 2017). Additionally, lipids are key components of membranes. The three main categories of membrane lipids, phospholipids, sphingolipids, and cholesterol (ergosterol) have been shown to play pivotal roles within the cell, especially in intracellular trafficking of a variety of materials (Chen et al., 2016a; Cuesta-Geijo et al., 2015; Zhang et al., 2016). Since they are crucial to the trafficking process, it is important for these three categories of lipids to be present in optimal concentrations to allow proper function and maintainance of cellular functions.

The results of this study shed light on the crucial role of membrane lipid balance in facilitating proper protein recycling. In particular, my results demonstrate the role of phospholipid balance in retrograde trafficking from the early and late endosomes to the 
Golgi. While in a prior study sphingolipids were depleted using genetic manipulations (Tani and Kuge, 2012), my work took an alternative approach to sphingolipid depletion via use of the pharmacological agent myriocin to inhibit the pathway. This approach allowed greater control of the experimental system, as well as providing insight into the severity of recycling defects at a wide range of sphingolipid concentrations. Additionally, through overexpression of Lcb1 under the $T E F$ promotor, I was able to investigate the impact of sphingolipid overaccumulation. My work and the work by Tani and Kuge converged on the finding that sphingolipid imbalance results in defects in trafficking of V-SNAREs, such as Snc1. However, their work overlooked the specific portion of the pathway that was defective, while my work extended investigation to include this question. Additionally, my results provide novel insight into the important role of the balance of phospholipids and ergosterol in proper protein recycling, since imbalance resulted in mistrafficking of Snc1 from the membrane of the daughter bud to either the membrane of the mother cell or to puncta within the cell.

While imbalance of phospholipids and sphingolipids had a drastic effect on proper protein recycling, ergosterol imbalance had a less severe impact. Although the entire reason for this is not yet known, and requires further investigation, it is likely that the severity of defects in lipid imbalance mutants depends on whether lipid precursors with similar structures are present in the membrane to compensate for lack of the mature form of the lipid. Since there are many genes involved in ergosterol synthesis, and the deletion strains used in this study involved the terminal steps of the pathway, it is likely that immature forms of ergosterol may be sufficient for proper functioning of the recycling pathway. In contrast, since the synthesis of $\mathrm{PIP}_{2}$ involves fewer steps, there are 
likely no suitable precursors present to mitigate the loss of the mature form of the lipid, leading to more severe defects in protein recycling in deletion strains. Similarly, since sphingolipid synthesis was inhibited at the first step of the pathway, the downstream species of the lipid would also be depleted, resulting in a lack of the lipids needed for proper protein recycling.

The recycling pathway has three main steps: endocytosis, retrograde trafficking from the endosomes to Golgi, and trafficking from the Golgi to the plasma membrane. My results allowed me to determine the step of the pathway that was defective during membrane lipid imbalance. Since Snc1 puncta were visible internally even in mutant cells (Figs. 1-3), I concluded that membrane lipid imbalance does not completely hinder the endocytic step of this pathway, even though the $S J L$ genes and MSS4 have been implicated in the endocytic process (De Camilli et al., 1996; Simonsen et al., 2001; Stefan et al., 2002; Stefan et al., 2005). The presence of these intracellular puncta indicate that, although endocytosis may be impaired, the endocytic pathway is not completely inhibited in membrane lipid mutants. Additionally, through the use of the truncated Snc1PEM, it was verified that the secretory pathway, including Golgi to plasma membrane trafficking, was functional in membrane lipid mutants (Fig. 4). Given that Snc1 is shuttled through the early endosomes, and Snc1 puncta were accumulated in phospholipid mutants, (Fig. 5), the defect in recycling of Snc1 is most likely due to defects in early endosome to Golgi transport, rather than in the first or last segments of the pathway, highlighting the important role of membrane lipid balance in this step of the pathway. Based on my results, I formulated a model in which the secretory pathway is normal, and endocytosis is not significantly impaired, but the trafficking between the 
early endosomes and Golgi is hindered, leading to accumulation of Snc1 primarily in the cytoplasm (Fig. 9).

GFP-Snc1 was seen to accumulate intracellularly in large vacuole-like structures in the $m s s 4^{t s}$ and $T E F-L C B 1$ strains. While this finding requires additional investigation using CellTracker ${ }^{\mathrm{TM}}$ Blue CMAC (7-amino-4-chloromethylcoumarin, ThermoFisher®) staining to confirm that these accumulations are indeed found at the vacuole, it indicates missorting of proteins to the degradation pathway, rather than the recycling pathway in this strain. Interestingly, Snc1 accumulated in the lumen of these structures, rather than being present at the rim of the vacuole. Normally, worn out or damaged proteins are ubiquitinated, then sent to the vacuole for degradation through the action of the ESCRT complex (Babst, 2011). Therefore, I speculate that in the $m s s 4^{t s}$ and TEF-LCB1 strains, the ESCRT complex may be overactive, leading to excessive ubiquitination and targeting of GFP-Snc1 for degradation, rather than recycling.

In light of the finding that trafficking from the early endosome to Golgi was defective, I reasoned that the parallel trafficking pathway from the late endosomes to Golgi was likely also defective in this scenario. I tested for defects in this pathway by expressing Vps10-GFP in these cells. Since Vps10 is a late endosome marker, the increased number of Vps10 puncta upon membrane lipid imbalance indicates that protein trafficking to the Golgi is hindered, resulting in an excess of late endosomes. Based on this, my model was refined to show hindrance of retrograde traffic from the late endosomes to Golgi (Fig. 9). Although we have not tested the effect of sphingolipids and ergosterol on late endosome to Golgi traffic, we would expect, based on the phospholipid data, similar results and mechanism. To our knowledge, Vps10 has not previously been 
used in the study of membrane lipid imbalance to track retrograde trafficking between the late endosomes and Golgi, and its use in the current study contributes to a greater knowledge of the extent of trafficking defects caused by membrane lipid imbalance.

\section{Mechanism of Protein Recycling Defects}

Since defects in both the early and late endosome to Golgi pathways were observed, the mechanism for the defect was investigated. The actin and microtubule cytoskeletons are important for intracellular trafficking, with the assistance of motor proteins such as myosin and dynein. In mammalian cells, microtubules have been shown to be important in endosome to Golgi traffic (Itin et al., 1999), and actin has also been implicated in this process (Loubery et al., 2008). Vesicles are transported between organelles along cytoskeletal fibers including actin fibers (Gunning et al., 2015). Therefore, the integrity of the actin network was of particular interest. Interestingly, phospholipid mutants were found to have disrupted cable systems, which is likely part of the mechanism of the defects observed in these strains. When actin cables are disturbed, intracellular trafficking would also be disturbed, leading to improper protein accumulation in the cytoplasm. When the membrane lipid balance is normal, the actin cables are intact, and retrograde traffic of Snc1 from the early endosomes to the Golgi, as well as retrograde traffic of Vps10 from the late endosomes to the Golgi, is normal (Fig. 10A). When there is an imbalance in the membrane lipids, the actin cables are disrupted, leading to a hindrance in retrograde traffic and accumulation of Snc1 and Vps10 in the cytoplasm (Fig. 10B). Currently, the mechanism by which membrane lipid imbalance 
disrupts actin cables is not yet known, and further studies are required to elucidate the interactions causing this disturbance.

Although the mobility of Vps10-GFP puncta was not found to be significantly different in wild type and phospholipid mutant strains, the speed at which the puncta disappeared from the focal plane varied significantly. While puncta in phospholipid mutants persisted for extended periods of time, the puncta in wild-type cells were much more dynamic, and disappeared after much briefer periods of time. Since the puncta were moving through the $\mathrm{Z}$ plane, accurate tracking of their mobility was not possible, and my results underestimate the true mobility of puncta in wild-type cells. Ideally, 4D imaging would be used to track these particles in the future, leading to greater insight on the impacts of membrane lipid imbalance on protein trafficking. 


\section{REFERENCES}

Alzheimer's, A. (2016). 2016 Alzheimer's disease facts and figures. Alzheimers Dement $12,459-509$.

Amberg, D.C., Burke, D.J., and Strathern, J.N. (2005). Methods in Yeast Genetics (New York: Cold Spring Laboratory Press).

Audhya, A., and Emr, S.D. (2003). Regulation of PI4,5P2 synthesis by nuclearcytoplasmic shuttling of the Mss4 lipid kinase. EMBO J 22, 4223-4236.

Babst, M. (2011). MVB vesicle formation: ESCRT-dependent, ESCRT-independent and everything in between. Curr Opin Cell Biol 23, 452-457.

Barton, D.H., Corrie, J.E., Bard, M., and Woods, R.A. (1974). Biosynthesis of terpenes and steroids. IX. The sterols of some mutant yeasts and their relationship to the biosynthesis of ergosterol. J Chem Soc Perkin 1 11, 1326-1333.

Benskey, M.J., Perez, R.G., and Manfredsson, F.P. (2016). The contribution of alpha synuclein to neuronal survival and function - Implications for Parkinson's disease. J Neurochem 137, 331-359.

Bettayeb, K., Hooli, B.V., Parrado, A.R., Randolph, L., Varotsis, D., Aryal, S., Gresack, J., Tanzi, R.E., Greengard, P., and Flajolet, M. (2016). Relevance of the COPI complex for Alzheimer's disease progression in vivo. Proc Natl Acad Sci U S A 113, 5418-5423.

Blagojevic Zagorac, G., Mahmutefendic, H., Macesic, S., Karleusa, L., and Lucin, P. (2017). Quantitative Analysis of Endocytic Recycling of Membrane Proteins by Monoclonal Antibody-Based Recycling Assays. J Cell Physiol 232, 463-476.

Brown, A.M., and Bevan, D.R. (2017). Influence of sequence and lipid type on membrane perturbation by human and rat amyloid beta-peptide (1-42). Arch Biochem Biophys 614, 1-13.

Brown, W.J., Goodhouse, J., and Farquhar, M.G. (1986). Mannose-6-phosphate receptors for lysosomal enzymes cycle between the Golgi complex and endosomes. J Cell Biol $103,1235-1247$. 
Bruno, M., Rizzo, I.M., Romero-Guevara, R., Bernacchioni, C., Cencetti, F., Donati, C., and Bruni, P. (2017). Sphingosine 1-phosphate signaling axis mediates fibroblast growth factor 2-induced proliferation and survival of murine auditory neuroblasts. Biochim Biophys Acta.

Buede, R., Rinker-Schaffer, C., Pinto, W.J., Lester, R.L., and Dickson, R.C. (1991). Cloning and characterization of LCB1, a Saccharomyces gene required for biosynthesis of the long-chain base component of sphingolipids. J Bacteriol 173, 4325-4332.

Burd, C., and Cullen, P.J. (2014). Retromer: a master conductor of endosome sorting. Cold Spring Harb Perspect Biol 6.

Burd, C.G. (2011). Physiology and pathology of endosome-to-Golgi retrograde sorting. Traffic 12, 948-955.

Buttery, S.M., Yoshida, S., and Pellman, D. (2007). Yeast formins Bni1 and Bnr1 utilize different modes of cortical interaction during the assembly of actin cables. Mol Biol Cell $18,1826-1838$.

Castro-Gomez, P., Rodriguez-Alcala, L.M., Monteiro, K.M., Ruiz, A.L., Carvalho, J.E., and Fontecha, J. (2016). Antiproliferative activity of buttermilk lipid fractions isolated using food grade and non-food grade solvents on human cancer cell lines. Food Chem 212, 695-702.

Cereghino, J.L., Marcusson, E.G., and Emr, S.D. (1995). The cytoplasmic tail domain of the vacuolar protein sorting receptor Vps10p and a subset of VPS gene products regulate receptor stability, function, and localization. Mol Biol Cell 6, 1089-1102.

Chen, D., Chen, M., Lu, Z., Yang, M., Xie, L., Zhang, W., Xu, H., Lu, K., and Lu, Y. (2016a). Cholesterol induces proliferation of chicken primordial germ cells. Anim Reprod Sci 171, 36-40.

Chen, D.C., Yang, B.C., and Kuo, T.T. (1992). One-step transformation of yeast in stationary phase. Curr Genet 21, 83-84.

Chen, L., Lau, M.S., and Banfield, D.K. (2016b). Multiple ER-Golgi SNARE transmembrane domains are dispensable for trafficking but required for SNARE recycling. Mol Biol Cell 27, 2633-2641. 
Cheney, R.E., and Baker, J.P. (1999). Myosins, divergent. In Guidebook to the Cytoskeletal and Motor Proteins, T.E. Kreis, and R. Vale, eds. (Oxford: Oxford University Press), pp. 453-456.

Connor, W.E., Lin, D.S., Thomas, G., Ey, F., DeLoughery, T., and Zhu, N. (1997). Abnormal phospholipid molecular species of erythrocytes in sickle cell anemia. J Lipid Res 38, 2516-2528.

Cooper, A.A., and Stevens, T.H. (1996). Vps10p cycles between the late-Golgi and prevacuolar compartments in its function as the sorting receptor for multiple yeast vacuolar hydrolases. J Cell Biol 133, 529-541.

Corcoles-Saez, I., Hernandez, M.L., Martinez-Rivas, J.M., Prieto, J.A., and Randez-Gil, F. (2016). Characterization of the S. cerevisiae inp51 mutant links phosphatidylinositol 4,5-bisphosphate levels with lipid content, membrane fluidity and cold growth. Biochim Biophys Acta 1861, 213-226.

Csoti, I., Jost, W.H., and Reichmann, H. (2016). Parkinson's disease between internal medicine and neurology. J Neural Transm (Vienna) 123, 3-17.

Cuesta-Geijo, M.A., Chiappi, M., Galindo, I., Barrado-Gil, L., Munoz-Moreno, R., Carrascosa, J.L., and Alonso, C. (2015). Cholesterol Flux Is Required for Endosomal Progression of African Swine Fever Virions during the Initial Establishment of Infection. J Virol 90, 1534-1543.

Daum, G., Lees, N.D., Bard, M., and Dickson, R. (1998). Biochemistry, cell biology and molecular biology of lipids of Saccharomyces cerevisiae. Yeast 14, 1471-1510.

De Camilli, P., Emr, S.D., McPherson, P.S., and Novick, P. (1996). Phosphoinositides as regulators in membrane traffic. Science 271, 1533-1539.

Dean-Johnson, M., and Henry, S.A. (1989). Biosynthesis of inositol in yeast. Primary structure of myo-inositol-1-phosphate synthase (EC 5.5.1.4) and functional analysis of its structural gene, the INO1 locus. J Biol Chem 264, 1274-1283.

Dong, R., Saheki, Y., Swarup, S., Lucast, L., Harper, J.W., and De Camilli, P. (2016). Endosome-ER Contacts Control Actin Nucleation and Retromer Function through VAPDependent Regulation of PI4P. Cell 166, 408-423. 
Doughman, R.L., Firestone, A.J., and Anderson, R.A. (2003). Phosphatidylinositol phosphate kinases put PI4,5P(2) in its place. J Membr Biol 194, 77-89.

Douglas, P.M., and Dillin, A. (2010). Protein homeostasis and aging in neurodegeneration. J Cell Biol 190, 719-729.

Dukes, J.D., Whitley, P., and Chalmers, A.D. (2012). The PIKfyve inhibitor YM201636 blocks the continuous recycling of the tight junction proteins claudin-1 and claudin-2 in MDCK cells. PLoS One 7, e28659.

Dupont, S., Beney, L., Ferreira, T., and Gervais, P. (2011). Nature of sterols affects plasma membrane behavior and yeast survival during dehydration. Biochim Biophys Acta $1808,1520-1528$.

Enrich, C., Rentero, C., Hierro, A., and Grewal, T. (2015). Role of cholesterol in SNARE-mediated trafficking on intracellular membranes. J Cell Sci 128, 1071-1081.

Fahy, E., Subramaniam, S., Murphy, R.C., Nishijima, M., Raetz, C.R., Shimizu, T., Spener, F., van Meer, G., Wakelam, M.J., and Dennis, E.A. (2009). Update of the LIPID MAPS comprehensive classification system for lipids. J Lipid Res 50 Suppl, S9-14.

Fecto, F., Esengul, Y.T., and Siddique, T. (2014). Protein recycling pathways in neurodegenerative diseases. Alzheimers Res Ther 6, 13.

Fernandez-Golbano, I.M., Idrissi, F.Z., Giblin, J.P., Grosshans, B.L., Robles, V., Grotsch, H., Borras Mdel, M., and Geli, M.I. (2014). Crosstalk between PI(4,5)P(2)and CK2 modulates actin polymerization during endocytic uptake. Dev Cell 30, 746-758.

Feyder, S., De Craene, J.O., Bar, S., Bertazzi, D.L., and Friant, S. (2015). Membrane trafficking in the yeast Saccharomyces cerevisiae model. Int J Mol Sci 16, 1509-1525.

Foth, B.J., Goedecke, M.C., and Soldati, D. (2006). New insights into myosin evolution and classification. Proc Natl Acad Sci U S A 103, 3681-3686.

Freedman, S.D., Katz, M.H., Parker, E.M., Laposata, M., Urman, M.Y., and Alvarez, J.G. (1999). A membrane lipid imbalance plays a role in the phenotypic expression of cystic fibrosis in cftr(-/-) mice. Proc Natl Acad Sci U S A 96, 13995-14000. 
Fujiwara, T., Misumi, Y., and Ikehara, Y. (1998). Dynamic recycling of ERGIC53 between the endoplasmic reticulum and the Golgi complex is disrupted by nordihydroguaiaretic acid. Biochem Biophys Res Commun 253, 869-876.

Fuller, K.L., Kuhlenschmidt, T.B., Kuhlenschmidt, M.S., Jimenez-Flores, R., and Donovan, S.M. (2013). Milk fat globule membrane isolated from buttermilk or whey cream and their lipid components inhibit infectivity of rotavirus in vitro. J Dairy Sci 96, 3488-3497.

Furuta, N., Fujimura-Kamada, K., Saito, K., Yamamoto, T., and Tanaka, K. (2007). Endocytic recycling in yeast is regulated by putative phospholipid translocases and the Ypt31p/32p-Rcylp pathway. Mol Biol Cell 18, 295-312.

Gao, L., and Bretscher, A. (2009). Polarized growth in budding yeast in the absence of a localized formin. Mol Biol Cell 20, 2540-2548.

Garcia-Gil, M., Pierucci, F., Vestri, A., and Meacci, E. (2017). Crosstalk between sphingolipids and vitamin D3: potential role in the nervous system. Br J Pharmacol.

Garcia-Melero, A., Reverter, M., Hoque, M., Meneses-Salas, E., Koese, M., Conway, J.R., Johnsen, C.H., Alvarez-Guaita, A., Morales-Paytuvi, F., Elmaghrabi, Y.A., et al. (2016). Annexin A6 and Late Endosomal Cholesterol Modulate Integrin Recycling and Cell Migration. J Biol Chem 291, 1320-1335.

Garcia-Ruiz, C., Ribas, V., Baulies, A., and Fernandez-Checa, J.C. (2016). Mitochondrial Cholesterol and the Paradox in Cell Death. Handb Exp Pharmacol.

Garzetti, G.G., Tranquilli, A.L., Cugini, A.M., Mazzanti, L., Cester, N., and Romanini, C. (1993). Altered lipid composition, increased lipid peroxidation, and altered fluidity of the membrane as evidence of platelet damage in preeclampsia. Obstet Gynecol 81, 337-340.

Goncalves, S.A., and Outeiro, T.F. (2016). Traffic jams and the complex role of alphaSynuclein aggregation in Parkinson disease. Small GTPases, 1-7.

Gualtierotti, R., Guarnaccia, L., Beretta, M., Navone, S.E., Campanella, R., Riboni, L., Rampini, P., and Marfia, G. (2017). Modulation of Neuroinflammation in the Central Nervous System: Role of Chemokines and Sphingolipids. Adv Ther. 
Gunning, P.W., Hardeman, E.C., Lappalainen, P., and Mulvihill, D.P. (2015).

Tropomyosin - master regulator of actin filament function in the cytoskeleton. J Cell Sci $128,2965-2974$.

Guo, S., Stolz, L.E., Lemrow, S.M., and York, J.D. (1999). SAC1-like domains of yeast SAC1, INP52, and INP53 and of human synaptojanin encode polyphosphoinositide phosphatases. J Biol Chem 274, 12990-12995.

Harterink, M., Port, F., Lorenowicz, M.J., McGough, I.J., Silhankova, M., Betist, M.C., van Weering, J.R., van Heesbeen, R.G., Middelkoop, T.C., Basler, K., et al. (2011). A SNX3-dependent retromer pathway mediates retrograde transport of the Wnt sorting receptor Wntless and is required for Wnt secretion. Nat Cell Biol 13, 914-923.

Hellhammer, J., Waladkhani, A.R., Hero, T., and Buss, C. (2010). Effects of milk phospholipid on memory and psychological stress response. British Food Journal 112, 1124-1137.

Hettema, E.H., Lewis, M.J., Black, M.W., and Pelham, H.R. (2003). Retromer and the sorting nexins Snx4/41/42 mediate distinct retrieval pathways from yeast endosomes. EMBO J 22, 548-557.

Hirokawa, N. (1998). Kinesin and dynein superfamily proteins and the mechanism of organelle transport. Science 279, 519-526.

Hon, G.M., Hassan, M.S., van Rensburg, S.J., Abel, S., van Jaarsveld, P., Erasmus, R.T., and Matsha, T. (2009). Red blood cell membrane fluidity in the etiology of multiple sclerosis. J Membr Biol 232, 25-34.

Idrissi, F.Z., and Geli, M.I. (2014). Zooming in on the molecular mechanisms of endocytic budding by time-resolved electron microscopy. Cell Mol Life Sci 71, 641-657.

Idrissi, F.Z., Grotsch, H., Fernandez-Golbano, I.M., Presciatto-Baschong, C., Riezman, H., and Geli, M.I. (2008). Distinct acto/myosin-I structures associate with endocytic profiles at the plasma membrane. J Cell Biol 180, 1219-1232.

Ikonen, E., and Holtta-Vuori, M. (2004). Cellular pathology of Niemann-Pick type C disease. Semin Cell Dev Biol 15, 445-454. 
Ikonen, E., and Jansen, M. (2008). Cellular sterol trafficking and metabolism: spotlight on structure. Curr Opin Cell Biol 20,371-377.

Itin, C., Ulitzur, N., Muhlbauer, B., and Pfeffer, S.R. (1999). Mapmodulin, cytoplasmic dynein, and microtubules enhance the transport of mannose 6-phosphate receptors from endosomes to the trans-golgi network. Mol Biol Cell 10, 2191-2197.

Johansen, J., Ramanathan, V., and Beh, C.T. (2012). Vesicle trafficking from a lipid perspective: Lipid regulation of exocytosis in Saccharomyces cerevisiae. Cell Logist 2, 151-160.

Jorgensen, M.U., Emr, S.D., and Winther, J.R. (1999). Ligand recognition and domain structure of Vps10p, a vacuolar protein sorting receptor in Saccharomyces cerevisiae. Eur J Biochem 260, 461-469.

Kavaliauskiene, S., Nymark, C.M., Bergan, J., Simm, R., Sylvanne, T., Simolin, H., Ekroos, K., Skotland, T., and Sandvig, K. (2014). Cell density-induced changes in lipid composition and intracellular trafficking. Cell Mol Life Sci 71, 1097-1116.

Keil, R., and Hatzfeld, M. (2014). The armadillo protein p0071 is involved in Rab11dependent recycling. J Cell Sci 127, 60-71.

Kitagaki, H., Cowart, L.A., Matmati, N., Montefusco, D., Gandy, J., de Avalos, S.V., Novgorodov, S.A., Zheng, J., Obeid, L.M., and Hannun, Y.A. (2009). ISC1-dependent metabolic adaptation reveals an indispensable role for mitochondria in induction of nuclear genes during the diauxic shift in Saccharomyces cerevisiae. J Biol Chem 284, 10818-10830.

Kitagaki, H., Cowart, L.A., Matmati, N., Vaena de Avalos, S., Novgorodov, S.A., Zeidan, Y.H., Bielawski, J., Obeid, L.M., and Hannun, Y.A. (2007). Isc1 regulates sphingolipid metabolism in yeast mitochondria. Biochim Biophys Acta 1768, 2849-2861.

Klug, L., and Daum, G. (2014). Yeast lipid metabolism at a glance. FEMS Yeast Res 14, 369-388.

Klupp, E., Grimmer, T., Tahmasian, M., Sorg, C., Yakushev, I., Yousefi, B.H., Drzezga, A., and Forster, S. (2015). Prefrontal hypometabolism in Alzheimer disease is related to longitudinal amyloid accumulation in remote brain regions. J Nucl Med 56, 399-404. 
Knop, M., Siegers, K., Pereira, G., Zachariae, W., Winsor, B., Nasmyth, K., and Schiebel, E. (1999). Epitope tagging of yeast genes using a PCR-based strategy: more tags and improved practical routines. Yeast 15, 963-972.

Kodedova, M., and Sychrova, H. (2015). Changes in the Sterol Composition of the Plasma Membrane Affect Membrane Potential, Salt Tolerance and the Activity of Multidrug Resistance Pumps in Saccharomyces cerevisiae. PLoS One 10, e0139306.

Kraemer, F.B., Shen, W.J., and Azhar, S. (2017). SNAREs and cholesterol movement for steroidogenesis. Mol Cell Endocrinol 441, 17-21.

Kuchta-Noctor, A.M., Murray, B.A., Stanton, C., Devery, R., and Kelly, P.M. (2016). Anticancer Activity of Buttermilk Against SW480 Colon Cancer Cells is Associated with Caspase-Independent Cell Death and Attenuation of Wnt, Akt, and ERK Signaling. Nutr Cancer 68, 1234-1246.

Kuypers, F.A. (2007). Membrane lipid alterations in hemoglobinopathies. Hematology Am Soc Hematol Educ Program, 68-73.

Lees, N.D., Skaggs, B., Kirsch, D.R., and Bard, M. (1995). Cloning of the late genes in the ergosterol biosynthetic pathway of Saccharomyces cerevisiae--a review. Lipids 30 , 221-226.

Lewis, M.J., Nichols, B.J., Prescianotto-Baschong, C., Riezman, H., and Pelham, H.R. (2000). Specific retrieval of the exocytic SNARE Snc1p from early yeast endosomes. Mol Biol Cell 11, 23-38.

Lima, S., Milstien, S., and Spiegel, S. (2017). Sphingosine and Sphingosine Kinase 1 Involvement in Endocytic Membrane Trafficking. J Biol Chem.

Liu, H., Radlowski, E.C., Conrad, M.S., Li, Y., Dilger, R.N., and Johnson, R.W. (2014). Early supplementation of phospholipids and gangliosides affects brain and cognitive development in neonatal piglets. J Nutr 144, 1903-1909.

Lo Presti, L., Chang, F., and Martin, S.G. (2012). Myosin Vs organize actin cables in fission yeast. Mol Biol Cell 23, 4579-4591.

Lock, J.G., and Stow, J.L. (2005). Rab11 in recycling endosomes regulates the sorting and basolateral transport of E-cadherin. Mol Biol Cell 16, 1744-1755. 
Loubery, S., Wilhelm, C., Hurbain, I., Neveu, S., Louvard, D., and Coudrier, E. (2008). Different microtubule motors move early and late endocytic compartments. Traffic 9 , 492-509.

Ma, M., Burd, C.G., and Chi, R.J. (2016). Distinct complexes of yeast Snx4 family SNXBARs mediate retrograde trafficking of Snc1 and Atg27. Traffic.

Marcusson, E.G., Horazdovsky, B.F., Cereghino, J.L., Gharakhanian, E., and Emr, S.D. (1994). The sorting receptor for yeast vacuolar carboxypeptidase $Y$ is encoded by the VPS10 gene. Cell 77, 579-586.

Martin, C.E., Oh, C.S., and Jiang, Y. (2007). Regulation of long chain unsaturated fatty acid synthesis in yeast. Biochim Biophys Acta 1771, 271-285.

McGough, I.J., Steinberg, F., Jia, D., Barbuti, P.A., McMillan, K.J., Heesom, K.J., Whone, A.L., Caldwell, M.A., Billadeau, D.D., Rosen, M.K., et al. (2014). Retromer binding to FAM21 and the WASH complex is perturbed by the Parkinson disease-linked VPS35(D620N) mutation. Curr Biol 24, 1670-1676.

Miyake, Y., Kozutsumi, Y., Nakamura, S., Fujita, T., and Kawasaki, T. (1995). Serine palmitoyltransferase is the primary target of a sphingosine-like immunosuppressant, ISP1/myriocin. Biochem Biophys Res Commun 211, 396-403.

Nagai, K. (2012). Bovine milk phospholipid fraction protects Neuro2a cells from endoplasmic reticulum stress via PKC activation and autophagy. J Biosci Bioeng 114, $466-471$.

Nagiec, M.M., Baltisberger, J.A., Wells, G.B., Lester, R.L., and Dickson, R.C. (1994). The LCB2 gene of Saccharomyces and the related LCB1 gene encode subunits of serine palmitoyltransferase, the initial enzyme in sphingolipid synthesis. Proc Natl Acad Sci U S A $91,7899-7902$.

Ng, M.L., Wadham, C., and Sukocheva, O.A. (2017). The role of sphingolipid signalling in diabetesassociated pathologies (Review). Int J Mol Med 39, 243-252.

Nikawa, J., Tsukagoshi, Y., and Yamashita, S. (1991). Isolation and characterization of two distinct myo-inositol transporter genes of Saccharomyces cerevisiae. J Biol Chem 266, 11184-11191. 
Parks, L.W., Smith, S.J., and Crowley, J.H. (1995). Biochemical and physiological effects of sterol alterations in yeast--a review. Lipids 30, 227-230.

Perez-Victoria, F.J., Mardones, G.A., and Bonifacino, J.S. (2008). Requirement of the human GARP complex for mannose 6-phosphate-receptor-dependent sorting of cathepsin D to lysosomes. Mol Biol Cell 19, 2350-2362.

Pichler, H., and Riezman, H. (2004). Where sterols are required for endocytosis. Biochim Biophys Acta 1666, 51-61.

Ren, H., Obike, I., Okpala, I., Ghebremeskel, K., Ugochukwu, C., and Crawford, M. (2005). Steady-state haemoglobin level in sickle cell anaemia increases with an increase in erythrocyte membrane n-3 fatty acids. Prostaglandins Leukot Essent Fatty Acids 72, 415-421.

Reverter, M., Rentero, C., de Muga, S.V., Alvarez-Guaita, A., Mulay, V., Cairns, R., Wood, P., Monastyrskaya, K., Pol, A., Tebar, F., et al. (2011). Cholesterol transport from late endosomes to the Golgi regulates t-SNARE trafficking, assembly, and function. Mol Biol Cell 22, 4108-4123.

Reverter, M., Rentero, C., Garcia-Melero, A., Hoque, M., Vila de Muga, S., AlvarezGuaita, A., Conway, J.R., Wood, P., Cairns, R., Lykopoulou, L., et al. (2014). Cholesterol regulates Syntaxin 6 trafficking at trans-Golgi network endosomal boundaries. Cell Rep 7, 883-897.

Ribas, V., Garcia-Ruiz, C., and Fernandez-Checa, J.C. (2016). Mitochondria, cholesterol and cancer cell metabolism. Clin Transl Med 5, 22.

Robinson, M.S. (2004). Adaptable adaptors for coated vesicles. Trends Cell Biol 14, 167174.

Schafer, J.C., McRae, R.E., Manning, E.H., Lapierre, L.A., and Goldenring, J.R. (2016). Rab11-FIP1A regulates early trafficking into the recycling endosomes. Exp Cell Res 340, $259-273$.

Schipper, L., van Dijk, G., Broersen, L.M., Loos, M., Bartke, N., Scheurink, A.J., and van der Beek, E.M. (2016). A Postnatal Diet Containing Phospholipids, Processed to Yield Large, Phospholipid-Coated Lipid Droplets, Affects Specific Cognitive Behaviors in Healthy Male Mice. J Nutr 146, 1155-1161. 
Schmitz, G., and Grandl, M. (2008). Lipid homeostasis in macrophages - implications for atherosclerosis. Rev Physiol Biochem Pharmacol 160, 93-125.

Schneiter, R. (1999). Brave little yeast, please guide us to thebes: sphingolipid function in S. cerevisiae. Bioessays 21, 1004-1010.

Schott, D., Ho, J., Pruyne, D., and Bretscher, A. (1999). The COOH-terminal domain of Myo2p, a yeast myosin V, has a direct role in secretory vesicle targeting. J Cell Biol 147, $791-808$.

Sen, A., Madhivanan, K., Mukherjee, D., and Aguilar, R.C. (2012). The epsin protein family: coordinators of endocytosis and signaling. Biomol Concepts 3, 117-126.

Simonsen, A., Wurmser, A.E., Emr, S.D., and Stenmark, H. (2001). The role of phosphoinositides in membrane transport. Curr Opin Cell Biol 13, 485-492.

Sorkin, A. (2004). Cargo recognition during clathrin-mediated endocytosis: a team effort. Curr Opin Cell Biol 16, 392-399.

Spincemaille, P., Matmati, N., Hannun, Y.A., Cammue, B.P., and Thevissen, K. (2014). Sphingolipids and mitochondrial function in budding yeast. Biochim Biophys Acta 1840, 3131-3137.

Stanishneva-Konovalova, T.B., Kelley, C.F., Eskin, T.L., Messelaar, E.M., Wasserman, S.A., Sokolova, O.S., and Rodal, A.A. (2016). Coordinated autoinhibition of F-BAR domain membrane binding and WASp activation by Nervous Wreck. Proc Natl Acad Sci U S A 113, E5552-5561.

Stefan, C.J., Audhya, A., and Emr, S.D. (2002). The yeast synaptojanin-like proteins control the cellular distribution of phosphatidylinositol (4,5)-bisphosphate. Mol Biol Cell $13,542-557$.

Stefan, C.J., Padilla, S.M., Audhya, A., and Emr, S.D. (2005). The phosphoinositide phosphatase Sj12 is recruited to cortical actin patches in the control of vesicle formation and fission during endocytosis. Mol Cell Biol 25, 2910-2923.

Stolz, A., and Wolf, D.H. (2012). Use of CPY and its derivatives to study protein quality control in various cell compartments. Methods Mol Biol 832, 489-504. 
Storrie, B. (2005). Maintenance of Golgi apparatus structure in the face of continuous protein recycling to the endoplasmic reticulum: making ends meet. Int Rev Cytol 244, 69-94.

Tani, M., and Kuge, O. (2012). Involvement of complex sphingolipids and phosphatidylserine in endosomal trafficking in yeast Saccharomyces cerevisiae. Mol Microbiol 86, 1262-1280.

Tehlivets, O., Scheuringer, K., and Kohlwein, S.D. (2007). Fatty acid synthesis and elongation in yeast. Biochim Biophys Acta 1771, 255-270.

TerBush, D.R., Maurice, T., Roth, D., and Novick, P. (1996). The Exocyst is a multiprotein complex required for exocytosis in Saccharomyces cerevisiae. EMBO J 15, 6483-6494.

Toshima, J.Y., Furuya, E., Nagano, M., Kanno, C., Sakamoto, Y., Ebihara, M., Siekhaus, D.E., and Toshima, J. (2016). Yeast Eps15-like endocytic protein Pan1p regulates the interaction between endocytic vesicles, endosomes and the actin cytoskeleton. Elife 5 .

Ueda, N. (2017). Sphingolipids in Genetic and Acquired Forms of Chronic Kidney Diseases. Curr Med Chem.

van Meer, G., Voelker, D.R., and Feigenson, G.W. (2008). Membrane lipids: where they are and how they behave. Nat Rev Mol Cell Biol 9, 112-124.

Vance, J.E. (2006). Lipid imbalance in the neurological disorder, Niemann-Pick C disease. FEBS Lett 580, 5518-5524.

Varandas, K.C., Irannejad, R., and von Zastrow, M. (2016). Retromer Endosome Exit Domains Serve Multiple Trafficking Destinations and Regulate Local G Protein Activation by GPCRs. Curr Biol 26, 3129-3142.

Veereman-Wauters, G., Staelens, S., Rombaut, R., Dewettinck, K., Deboutte, D., Brummer, R.J., Boone, M., and Le Ruyet, P. (2012). Milk fat globule membrane (INPULSE) enriched formula milk decreases febrile episodes and may improve behavioral regulation in young children. Nutrition $28,749-752$.

Wang, S., and Bellen, H.J. (2015). The retromer complex in development and disease. Development 142, 2392-2396. 
Wang, W., Wang, X., Fujioka, H., Hoppel, C., Whone, A.L., Caldwell, M.A., Cullen, P.J., Liu, J., and Zhu, X. (2016). Parkinson's disease-associated mutant VPS35 causes mitochondrial dysfunction by recycling DLP1 complexes. Nat Med 22, 54-63.

Wang, Y.J., Wang, J., Sun, H.Q., Martinez, M., Sun, Y.X., Macia, E., Kirchhausen, T., Albanesi, J.P., Roth, M.G., and Yin, H.L. (2003). Phosphatidylinositol 4 phosphate regulates targeting of clathrin adaptor AP-1 complexes to the Golgi. Cell 114, 299-310.

Wiederkehr, A., Avaro, S., Prescianotto-Baschong, C., Haguenauer-Tsapis, R., and Riezman, H. (2000). The F-box protein Rcylp is involved in endocytic membrane traffic and recycling out of an early endosome in Saccharomyces cerevisiae. J Cell Biol 149, 397-410.

Zhang, J.Y., Duan, Z.P., Zhang, J.L., and Zheng, S.J. (2016). [Research advances in the role of sphingolipids in HCV and HBV life cycles]. Zhonghua Gan Zang Bing Za Zhi 24, 945-947.

Zhang, X., St Clair, J.R., London, E., and Raleigh, D.P. (2017). Islet Amyloid Polypeptide Membrane Interactions: Effects of Membrane Composition. Biochemistry 56, 376-390.

Zinser, E., Paltauf, F., and Daum, G. (1993). Sterol composition of yeast organelle membranes and subcellular distribution of enzymes involved in sterol metabolism. J Bacteriol 175, 2853-2858. 
Table 1. Yeast strains used in this study.

\begin{tabular}{|c|c|c|}
\hline Strain number & Source & Genotype \\
\hline KKY 0002 & Invitrogen & 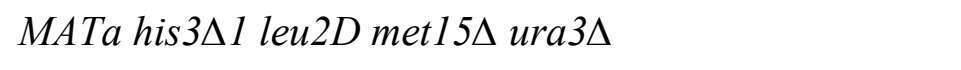 \\
\hline KKY 0038 & This study &  \\
\hline KKY 0040 & This study & 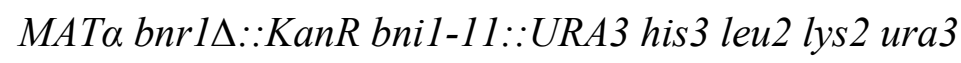 \\
\hline KKY 0074 & This study & MATa his $3 \Delta 1$ leu $2 \Delta 0$ met $15 \Delta 0$ ura3 $\Delta 0$ ERG3::KanMX6 \\
\hline KKY 0075 & This study & MATa his $3 \Delta 1$ leu $2 \Delta 0$ met $15 \Delta 0$ ura3 $\Delta 0$ ERG6::KanMX6 \\
\hline KKY 0197 & Invitrogen & MATa his $3 \Delta l e u 2 \Delta l y s 2 \Delta u r a 3 \Delta$ \\
\hline KKY 0352 & This study & MATa his $3 \Delta u r a \Delta l e u \Delta t r p \Delta l y s \Delta$ VPS1::KanMx6 \\
\hline KKY 0419 & This study & 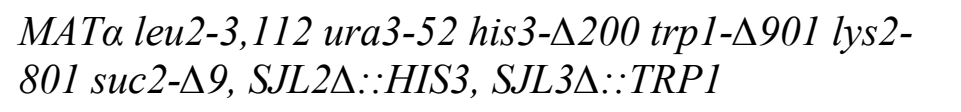 \\
\hline KKY 0420 & This study &  \\
\hline KKY 0421 & This study & 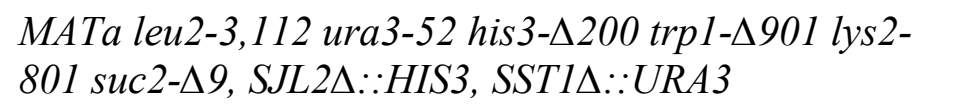 \\
\hline KKY 0422 & This study & 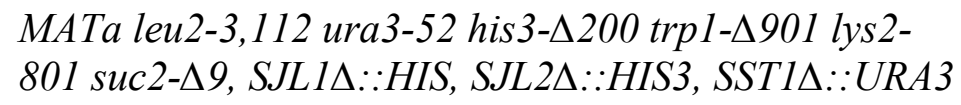 \\
\hline KKY 0423 & This study & 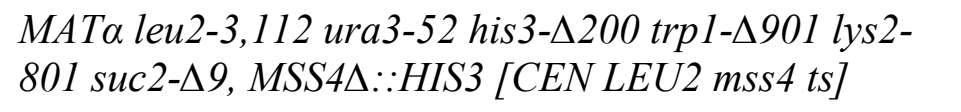 \\
\hline KKY 0818 & This study & MATa his $\Delta \operatorname{trp} \Delta m e t \Delta l y s \Delta$, ERG4::HIS, ERG6::KanMX6 \\
\hline KKY 0819 & This study & MATa his $\Delta$ trp $\Delta m e t \Delta$, ERG4::HIS, ERG6::KanMX6 \\
\hline KKY 1415 & This study & KKY 0075 (pRS416-GFP-Snc1) \\
\hline KKY 1416 & This study & KKY $0074(p R S 416-G F P-S n c 1)$ \\
\hline KKY 1417 & This study & KKY 0818 (pRS416-GFP-Snc1) \\
\hline KKY 1444 & This study & KKY 0002 (pRS416-GFP-Snc1) \\
\hline KKY 1446 & This study & KKY $0423(p R S 416-G F P-S n c 1)$ \\
\hline KKY 1447 & This study & KKY 0607 (pRS416-GFP-Snc1) \\
\hline KKY 1448 & This study & KKY $0420(p R S 315-G F P-S n c 1)$ \\
\hline
\end{tabular}


Table 1, continued.

\begin{tabular}{|c|c|c|}
\hline Strain number & Source & Genotype \\
\hline KKY 1449 & This study & KKY $0421(p R S 315-G F P-S n c 1)$ \\
\hline KKY 1450 & This study & KKY 0422 (pRS315-GFP-Snc1) \\
\hline KKY 1451 & This study & KKY 0419 (pRS416-GFP-Snc1) \\
\hline KKY 1457 & This study & KKY 0002 (pRS416-GFP-Snc1-PEM) \\
\hline KKY 1525 & This study & KKY 0002 (pRS315-GFP-Snc1) \\
\hline KKY 1565 & This study & KKY 0423 (pRS416-GFP-Snc1-PEM) \\
\hline KKY 1573 & This study & KKY 0417 (pRS416-GFP-Snc1-PEM) \\
\hline KKY 1574 & This study & KKY 0419 (pRS416-GFP-Snc1-PEM) \\
\hline KKY 1575 & This study & KKY 0607 (pRS416-GFP-Snc1-PEM) \\
\hline KKY 1612 & This study & KKY 1444 (pRS425-TEF-LCB1) \\
\hline KKY 1613 & This study & KKY 0075 (pRS416-GFP-Snc1-PEM) \\
\hline KKY 1614 & This study & KKY 0074 (pRS416-GFP-Snc1-PEM) \\
\hline KKY 1615 & This study & KKY 1525 (pRS425-TEF-Erg4) \\
\hline KKY 1786 & This study & KKY 420 Vps10-GFP-Trp \\
\hline KKY 1787 & This study & KKY 421 Vps10-GFP-Trp \\
\hline KKY 1788 & This study & KKY 422 Vps10-GFP-Trp \\
\hline KKY 1820 & This study & KKY 197 Vps10-GFP-His3MX6 \\
\hline
\end{tabular}


Table 2. Bacterial plasmids used in this study.

\begin{tabular}{lll}
\hline Plasmid Number & Source & Plasmid Name \\
\hline KKD 0061 & (Furuta et al., 2007) & pRS416-GFP-Snc1 \\
KKD 0062 & (Furuta et al., 2007) & pRS416-GFP-Snc1-PEM \\
KKD 0064 & (Furuta et al., 2007) & pRS315-GFP-Snc1 \\
KKD 0094 & Phil Hieter & pRS314 \\
KKD 0126 & Phil Hieter & pRS425 \\
KKD 0145 & Hokkaido University & pRS416-TEF-Ste2-mRFP \\
KKD 0233 & This study & pRS425-TEF \\
KKD 0281 & This study & pRS425-TEF-LCB1 \\
KKD 0283 & This study & pRS425-TEF-Erg4 \\
KKD 0293 & This study & pRS314-TEF \\
KKD 0317 & This study & pRS314-TEF-Gga1 \\
KKD 0319 & This study & pRS314-TEF-Gga1-mRFP \\
\hline
\end{tabular}


Table 3. Oligonucleotides used in this study.

\begin{tabular}{|c|c|c|}
\hline $\begin{array}{l}\text { Primer } \\
\text { Number }\end{array}$ & Primer Name & Sequence \\
\hline KKР726 & $\begin{array}{l}\text { Ggal in p314 TEF, } \\
\text { reverse }\end{array}$ & $\begin{array}{l}\text { 5'-GACATGGATCCTATTGTGGGCAAACTGGT } \\
\text { CGTGC-3' }\end{array}$ \\
\hline KKP731 & $\begin{array}{l}\text { LCB1 in PRS425, } \\
\text { forward }\end{array}$ & $\begin{array}{l}\text { 5'-CACTGGATCCATGGCACACATCCCAGAGG } \\
\text { TTTTACC-3' }\end{array}$ \\
\hline KKР732 & $\begin{array}{l}\mathrm{LCB} 1 \text { in PRS425, } \\
\text { reverse }\end{array}$ & $\begin{array}{l}\text { 5'-CATCCTCGAGTTATTTATTAGATTCTTGGC } \\
\text { AACAGGCAAGGATGG-3' }\end{array}$ \\
\hline KКР749 & $\begin{array}{l}\text { Erg4 in TEF PRS425, } \\
\text { forward }\end{array}$ & $\begin{array}{l}\text { 5'-CACTGGGATCCATGGCAAAGGATAATAGT } \\
\text { GAGAAGCTGCAGGT-3' }\end{array}$ \\
\hline KKP750 & $\begin{array}{l}\text { Erg4 in TEF PRS425, } \\
\text { reverse }\end{array}$ & $\begin{array}{l}\text { 5'-CACTGCTCGAGCTAGAAAACATAAGGAAT } \\
\text { AAAGACGTAAGGGCA-3' }\end{array}$ \\
\hline KКР773 & $\begin{array}{l}\text { Vps } 10 \text { GFP tagging, } \\
\text { forward }\end{array}$ & $\begin{array}{l}\text { 5'-GAAGGAAATGAGGAAAACATCGACAGGC } \\
\text { CTGATTCTACAGCGCCATCTAACGAAAACCA } \\
\text { GCGGATCCCCGGGTTAATTAA-3' }\end{array}$ \\
\hline KKР774 & $\begin{array}{l}\text { Vps } 10 \text { GFP tagging, } \\
\text { reverse }\end{array}$ & $\begin{array}{l}\text { 5'-CTGCTCGTTTTTGTTTATGAAAAGTATATG } \\
\text { GAATTATCTACTCTATGTAAAGTAATCTCTG } \\
\text { AATTCGACTCGTTTAAAC-3' }\end{array}$ \\
\hline KKР797 & $\begin{array}{l}\text { Gga1 in p314 TEF, } \\
\text { forward }\end{array}$ & $\begin{array}{l}\text { 5'-GACAGCGGCCGCATGCCACAAAGAATTGA } \\
\text { GCTTACCTCCGAA-3' }\end{array}$ \\
\hline
\end{tabular}





Figure 1. Characterization of the localization of GFP-Snc1 in wild type and phospholipid mutant cells A) Representative images of wild type (positive control) and phospholipid mutant cells. $m s s 4^{t s}$ cells were grown at an elevated temperature $\left.\left(37^{\circ} \mathrm{C}\right) \mathbf{B}\right)$ Percent of cells showing GFP-Snc1 polarization. Quantification was performed on 3 sets of 30 cells each. $* \mathrm{p}<0.05, * * \mathrm{p}<0.01, * * * \mathrm{p}<0.001$. 

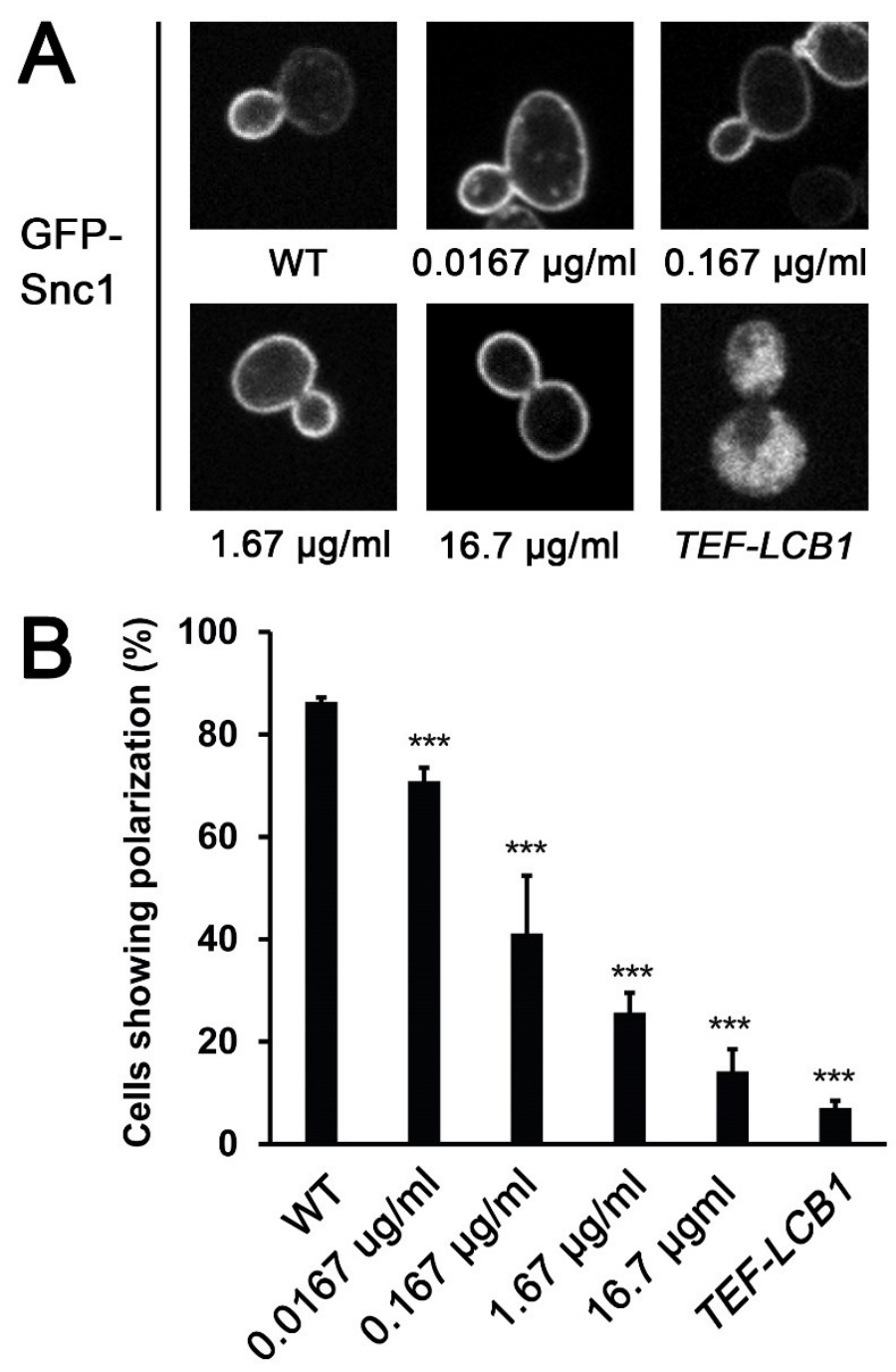

Figure 2. Characterization of the localization of GFP-Snc1 in wild-type, sphingolipid mutant and sphingolipid-overexpressing cells A) Representative images of wild-type and sphingolipid vand sphingolipid-overexpressing cells. B) Percent of cells showing GFPSnc1 polarization. Quantification was performed on 3 sets of 30 cells each. ${ }^{*} p<0.05$, ** $\mathrm{p}<0.01, * * * \mathrm{p}<0.001$. 


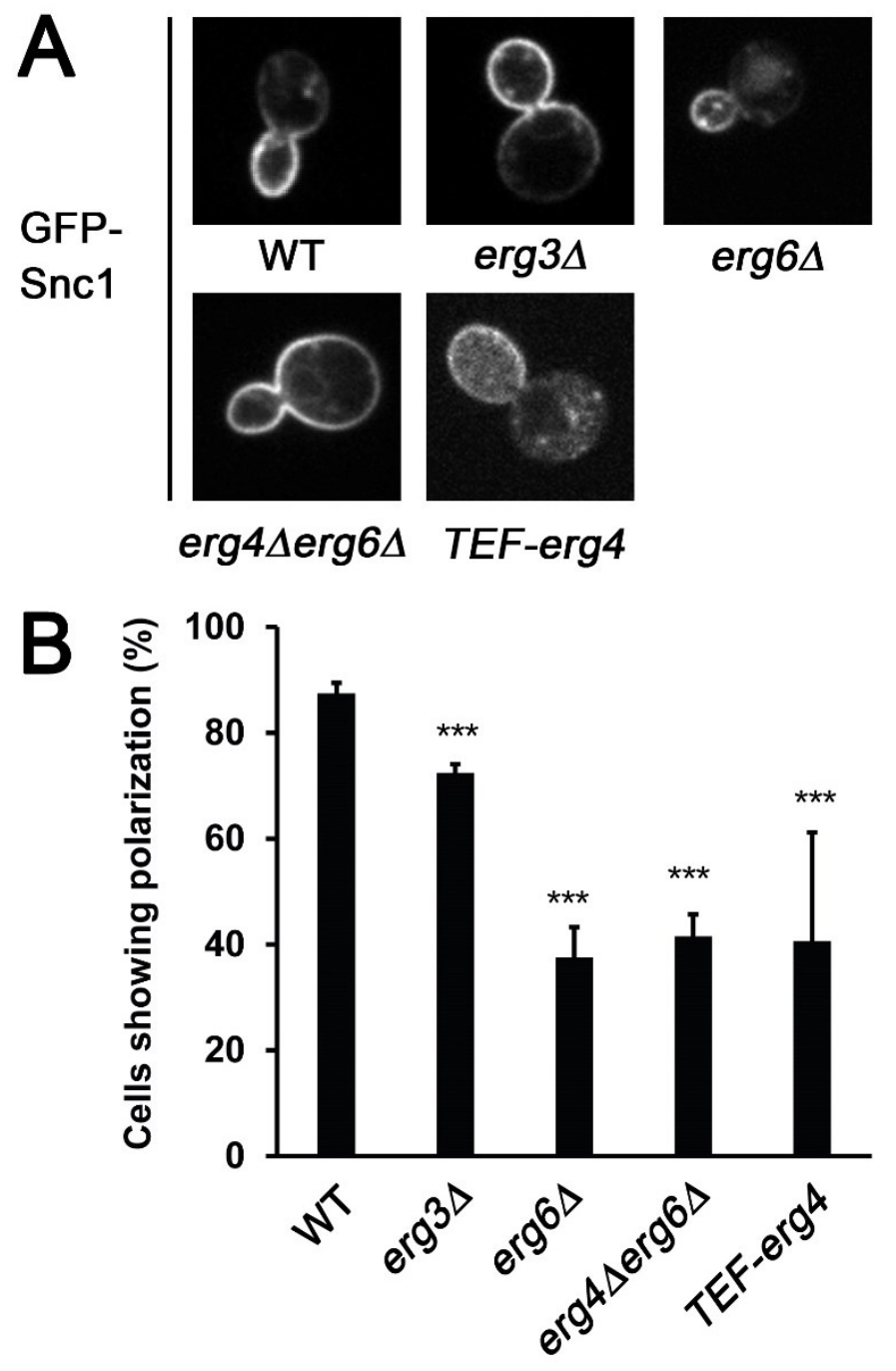

Figure 3. Characterization of the localization of GFP-Snc1 in wild-type, ergosterol mutant and ergosterol-overexpressing cells A) Representative images of wild-type, ergosterol mutant and ergosterol-overexpressing cells. B) Percent of cells showing GFPSnc1 polarization. Quantification was performed on 3 sets of 30 cells each. ${ }^{*} \mathrm{p}<0.05$, ** $\mathrm{p}<0.01, * * * \mathrm{p}<0.001$ 


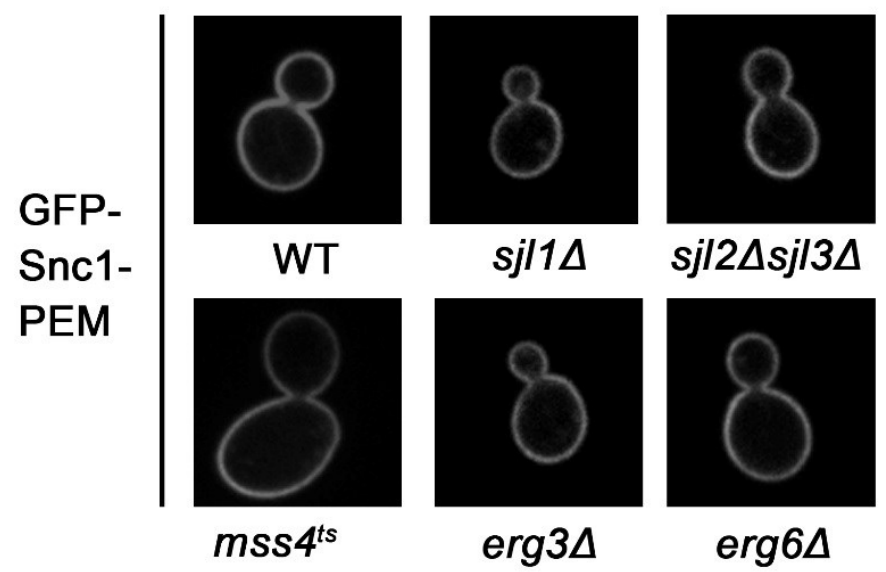

Figure 4. Localization of Snc1-GFP-PEM in wild-type and membrane lipid mutants. Wild-type and mutant strains exhibit similar phenotypes, indicating the secretory pathway is normal in membrane lipid mutants. 

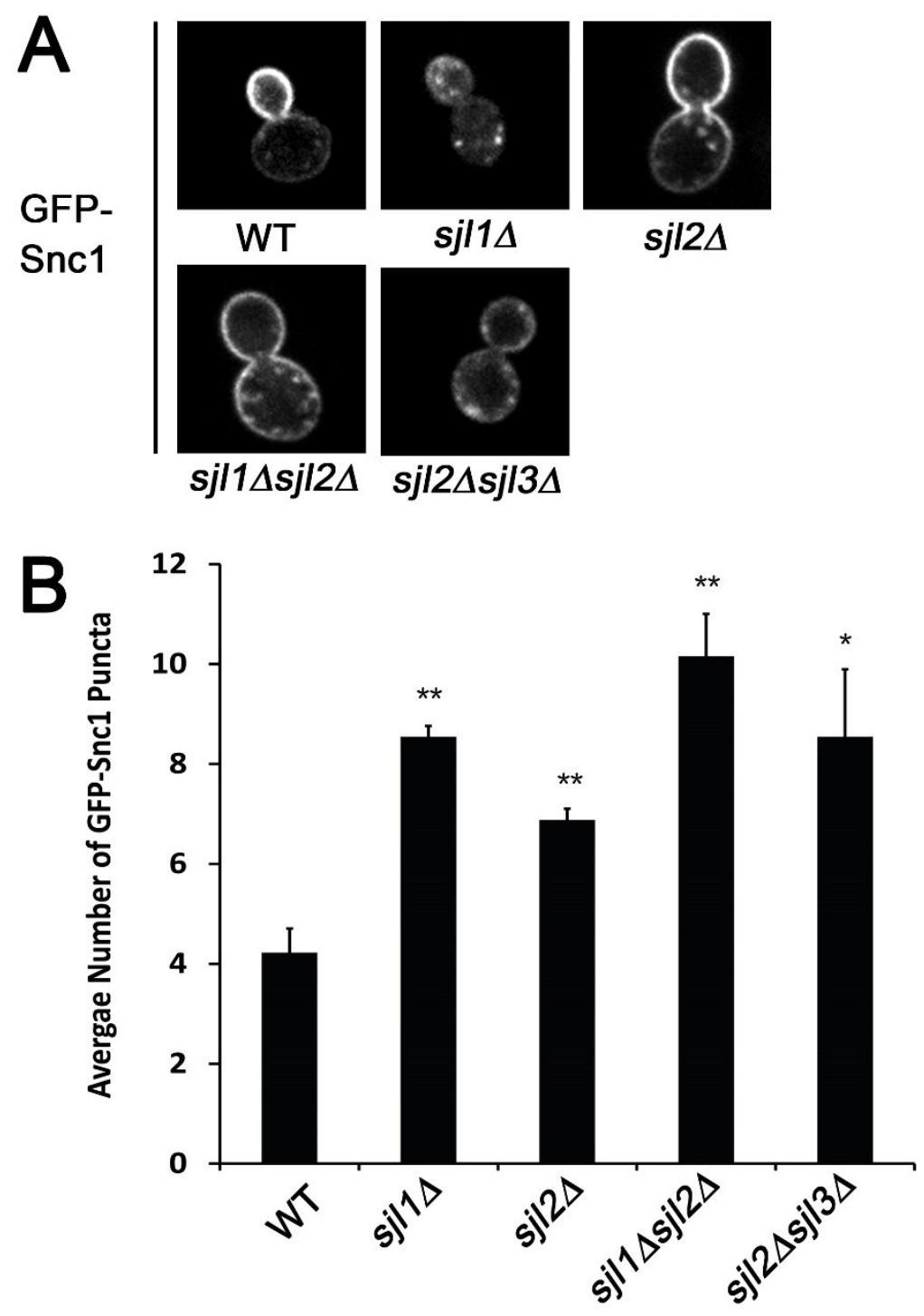

Figure 5. GFP-Snc1 puncta accumulate in phospholipid mutants. A) Representative images of GFP-Snc1 puncta in wild type and membrane lipid mutants. B). Quantification of average number of GFP-Snc1 puncta per cell in wild type and phospholipid mutant strains. ${ }^{*} \mathrm{p}<0.05, * * \mathrm{p}<0.01$. 

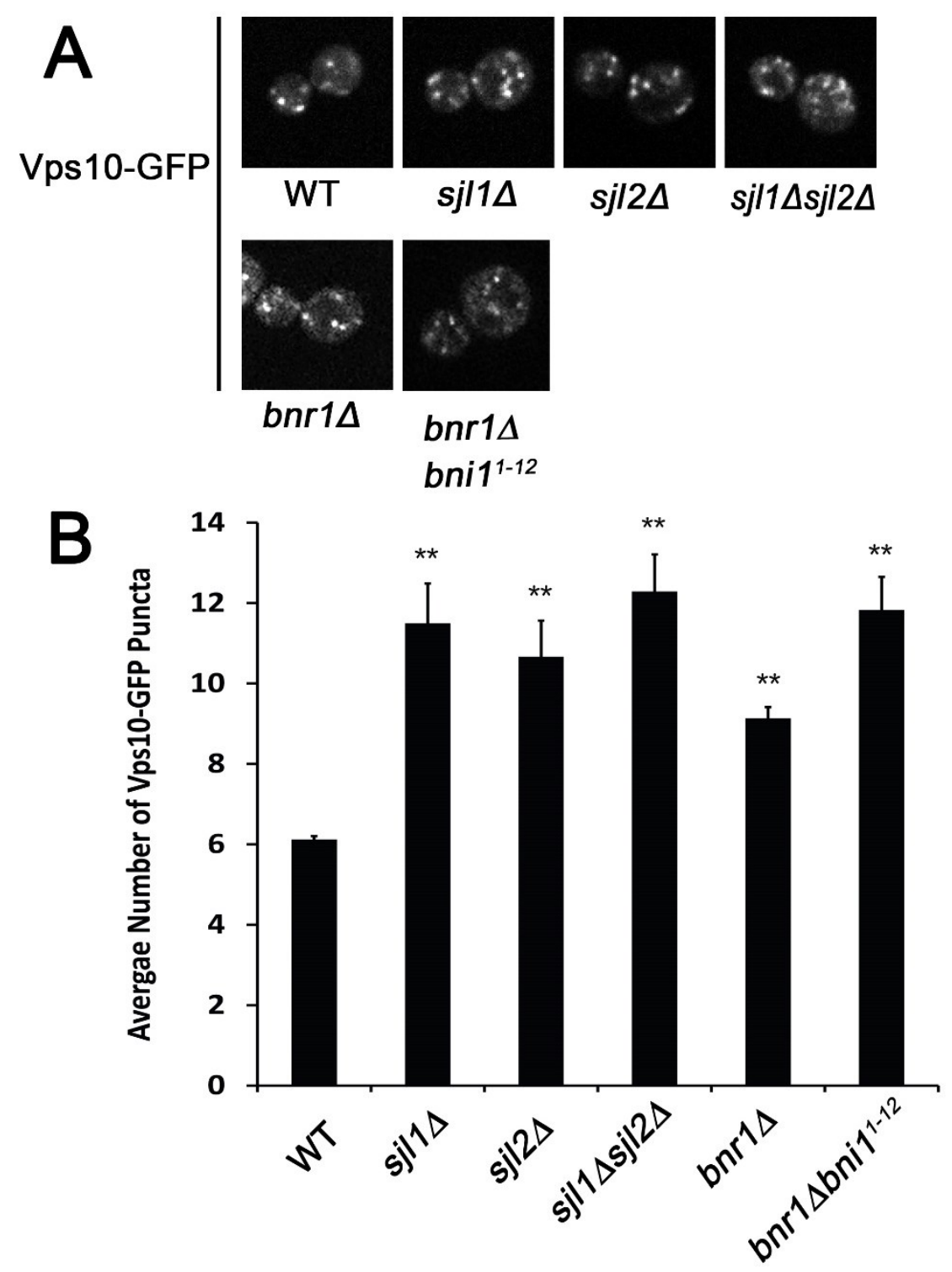

Figure 6. Vps10 puncta accumulate in membrane lipid mutants. A). Representative images of GFP-Vps10 localization in wild-type and mutant strains. B). Quantification of number of Vps10-GFP puncta present in wild type and mutant strains, 3 sets of 30 cells each. $* * \mathrm{p}<0.01$. 

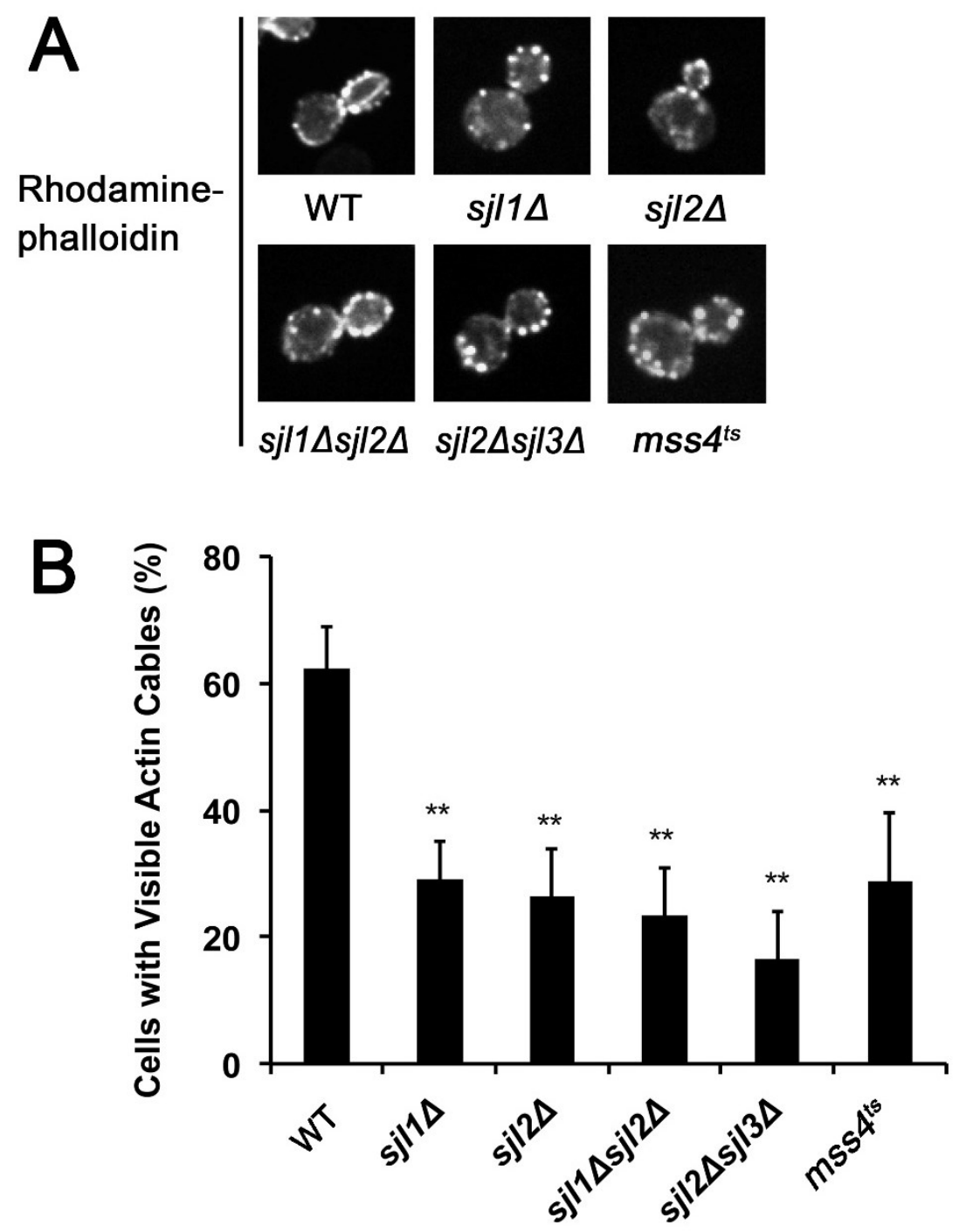

Figure 7. Actin cables are diminished in membrane lipid mutants. A). Representative images of cells stained with rhodamine-phalloidin dye to detect the presence of actin cables. B). Quantification of percent of cells with visible actin cables, 3 sets of 30 cells each. $* * \mathrm{p}<0.01$. 




Figure 8. Average distance traveled by Vps10-GFP puncta. Cells were live-imaged at 2 frames/sec for $60 \mathrm{sec}$. Puncta that appeared and persisted for at least 15 seconds were manually tracked using ImageJ software, from the time of appearance for 15 seconds. In each frame, the location of the dot was marked, and Excel was used to calculate total distance traveled over 15 seconds. There was no significant difference between distance traveled by Vps1-GFP dots in the control and mutant strains. 



Figure 9. Model of Snc1 trafficking in yeast. In the synthetic pathway (black arrows), Sncl is synthesized at the endoplasmic reticulum, then trafficked through the early and late Golgi to the plasma membrane. In the recycling pathway, Snc1 is endocytosed to the early endosomes, then trafficked to the Golgi (retrograde trafficking) and then back to the plasma membrane. In membrane lipid imbalance, there is a defect in retrograde (endosome to Golgi) trafficking, which results in accumulation of Snc1 at the early endosomes. The parallel pathway from the late endosomes to the Golgi is also defective, resulting in accumulation of Vps10 at the late endosomes. 
A WT membrane lipid levels - normal traffic

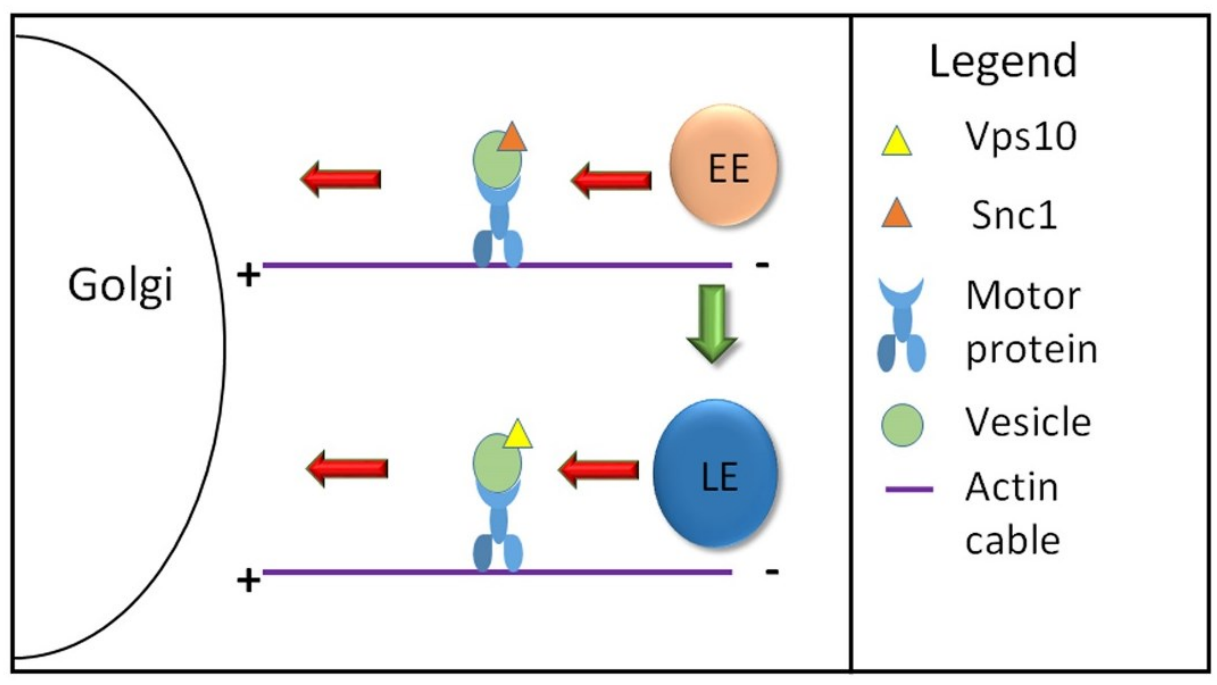

B Membrane lipid imbalance - traffic hindered

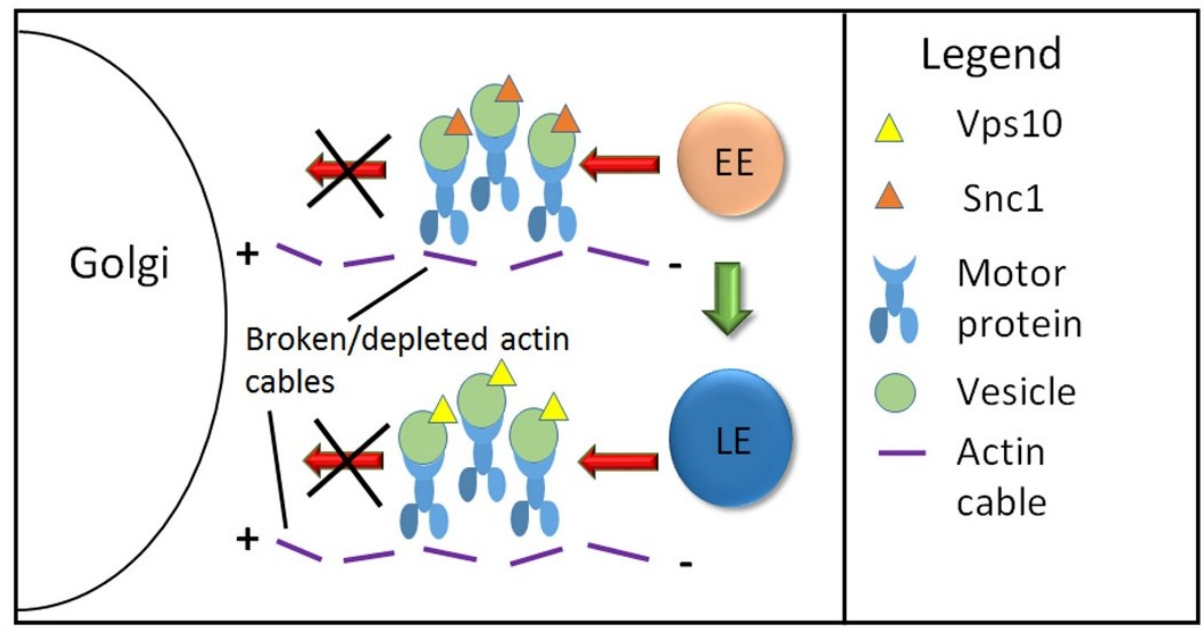

Figure 10. Model of trafficking defects observed due to membrane lipid imbalance. A) In wild-type cells, traffic is normal, with Snc1-carrying vesicles being transported along actin cables from the early endosomes to the Golgi, and Vps10-carrying vesicles being transported from the late endosomes to the Golgi. B) In membrane lipid imbalance cells, actin cables are depleted, and traffic of Snc1- and Vps10-carrying vesicles from the early and late endosomes, respectively, to the Golgi is hindered. This results in protein accumulation at the endosomes. 